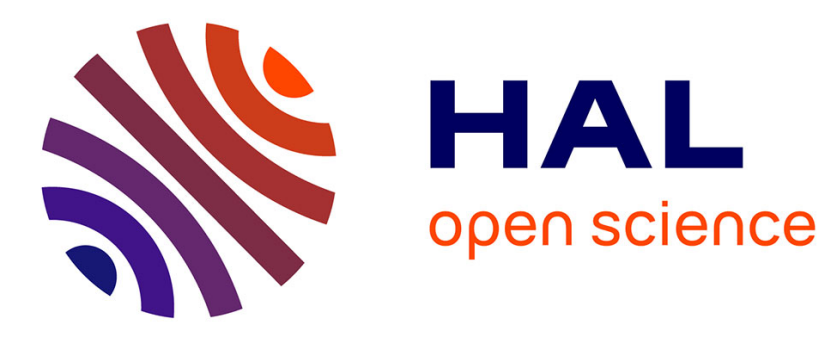

\title{
Presenilin 1 mutation decreases both calcium and contractile responses in cerebral arteries
}

\author{
Xavier Toussay, Jean-Luc Morel, Nathalie Biendon, Lolita Rotureau, \\ François-Pierre Legeron, Marie-Charlotte Boutonnet, Yoon H Cho, Nathalie \\ Macrez
}

\section{To cite this version:}

Xavier Toussay, Jean-Luc Morel, Nathalie Biendon, Lolita Rotureau, François-Pierre Legeron, et al.. Presenilin 1 mutation decreases both calcium and contractile responses in cerebral arteries. Neurobiology of Aging, 2017, 58, pp.201 - 212. 10.1016/j.neurobiolaging.2017.06.015 . hal-03006963

\section{HAL Id: hal-03006963 https://hal.science/hal-03006963}

Submitted on 16 Nov 2020

HAL is a multi-disciplinary open access archive for the deposit and dissemination of scientific research documents, whether they are published or not. The documents may come from teaching and research institutions in France or abroad, or from public or private research centers.
L'archive ouverte pluridisciplinaire $\mathbf{H A L}$, est destinée au dépôt et à la diffusion de documents scientifiques de niveau recherche, publiés ou non, émanant des établissements d'enseignement et de recherche français ou étrangers, des laboratoires publics ou privés. 


\title{
Presenilin 1 mutation decreases both calcium and contractile responses in cerebral arteries
}

\author{
Xavier Toussay ${ }^{\mathrm{a}, \mathrm{b}, 1}$, Jean-Luc Morel ${ }^{\mathrm{a}, \mathrm{c}}$, Nathalie Biendon ${ }^{\mathrm{a}, \mathrm{c}}$, Lolita Rotureau $^{\mathrm{a}, \mathrm{b}}$, \\ François-Pierre Legeron ${ }^{\mathrm{a}, \mathrm{c}}$, Marie-Charlotte Boutonnet ${ }^{\mathrm{a}, \mathrm{c}}$, Yoon H. Cho ${ }^{\mathrm{d}}$, \\ Nathalie Macrez ${ }^{\text {a,c,* }}$ \\ ${ }^{a}$ University Bordeaux, Institut des Maladies Neurodégénératives, UMR 5293, Bordeaux, France \\ ${ }^{\mathrm{b}}$ CNRS, Centre de Neurosciences Intégratives et Cognitives, UMR 5228, Bordeaux, France \\ ${ }^{\mathrm{c}}$ CNRS, Institut des Maladies Neurodégénératives, UMR 5293, Bordeaux, France \\ ${ }^{\mathrm{d}}$ CNRS, Institut de Neurosciences Cognitives et Intégratives d'Aquitaine, UMR 5287, Bordeaux, France
}

\section{A R T I C L E I N F O}

Article history:

Received 7 November 2016

Received in revised form 9 June 2017

Accepted 19 June 2017

Available online 24 June 2017

\section{Keywords:}

Presenilin

Calcium

Smooth muscle cells

Contraction

Cerebral arteries

Alzheimer's disease

\begin{abstract}
A B S T R A C T
Mutations or upregulation in presenilin 1 (PS1) gene are found in familial early-onset Alzheimer's disease or sporadic late-onset Alzheimer's disease, respectively. PS1 has been essentially studied in neurons and its mutation was shown to alter intracellular calcium $\left(\mathrm{Ca}^{2+}\right)$ signals. Here, we showed that PS1 is expressed in smooth muscle cells (SMCs) of mouse cerebral arteries, and we assessed the effects of the deletion of exon 9 of PS1 (PS1dE9) on $\mathrm{Ca}^{2+}$ signals and contractile responses of vascular SMC. Agonistinduced contraction of cerebral vessels was significantly decreased in PS1dE9 both in vivo and ex vivo. Spontaneous activity of $\mathrm{Ca}^{2+}$ sparks through ryanodine-sensitive channels (RyR) was unchanged, whereas the RyR-mediated $\mathrm{Ca}^{2+}$-release activated by caffeine was shorter in PS1dE9 SMC when compared with control. Moreover, PS1dE9 mutation decreased the caffeine-activated capacitive $\mathrm{Ca}^{2+}$ entry, and inhibitors of SERCA pumps reversed the effects of PS1dE9 on $\mathrm{Ca}^{2+}$ signals. PS1dE9 mutation also leads to the increased expression of SERCA3, phospholamban, and RyR3. These results show that PS1 plays a crucial role in the cerebrovascular system and the vascular reactivity is decreased through altered $\mathrm{Ca}^{2+}$ signals in PS1dE9 mutant mice.
\end{abstract}

(c) 2017 Elsevier Inc. All rights reserved.

\section{Introduction}

Recent hypotheses suggest that the disruption of the finely balanced interactions between neuronal neurotransmission and its neuro-vascular blood supply might promote the onset of Alzheimer's disease (AD; Marchesi, 2014). Cerebrovascular dysfunction such as damaged blood vessels and/or altered local blood flow leads to faulty beta amyloid peptide $(A \beta)$ clearance from the brain (Deane et al., 2004a,b) resulting in an overwhelmed drainage machinery and localized accumulations of $A \beta$ peptides in the brain (Marchesi, 2014). Both structural and functional defects of blood vessels have been shown in AD. Cerebral and systemic microvascular architecture is damaged in mouse model of AD (Kelly et al., 2015) and in human AD (Fischer et al., 1990; Kitaguchi et al., 2007). In addition,

\footnotetext{
* Corresponding author at: Institut des Maladies Neurodégénératives (IMN), CNRS UMR 5293, Université de Bordeaux, Allée Geoffroy St Hillaire Bât B2, F-33615 Pessac, France. Tel.: +33 5400088 30; fax: +33 556986182.

E-mail address: nathalie.macrez@u-bordeaux.fr (N. Macrez).

1 Present address: Faculty of Medicine, Department of Cellular and Molecular Medicine, University of Ottawa, The Ottawa Hospital Research Institute, Ottawa, ON, Canada.
}

microvessels responsiveness is impaired in patient suffering of mild cognitive impairment (Khalil et al., 2007) and arterial hypoperfusion and cerebral blood flow (CBF) dysregulation have been shown to precede cerebral atrophy and brain accumulation of $A \beta$ in AD (Iadecola, 2004; Zlokovic, 2005). Given that arterial contraction is the driving force for perivascular drainage and $A \beta$ clearance, the study of vascular reactivity may also have relevance for understanding the progression of amyloid pathology in AD. However, the molecular and cellular basis of Alzheimer's CBF dysregulation is poorly understood. Regulation of transcription factors leading to phenotypic modifications seems to be part of these mechanisms. Indeed, cerebral arteries derived from $\mathrm{AD}$ patients and $\mathrm{AD}$ models overexpress serum response factor/myocardin transcription factors and several serum response factor/myocardin-regulated contractile proteins mediating arterial hyper-contractility and CBF dysregulation (Chow et al., 2007). In addition, the fine tuning of calcium $\left(\mathrm{Ca}^{2+}\right)$ signaling in vascular smooth muscle cells (VSMCs) of cerebral arteries is critical for cerebral blood flow regulation (Dabertrand et al., 2013; Macrez and Mironneau, 2004; Morel et al., 2007; Wellman et al., 2002) and could be one important mechanism deregulated in the pathological process. Interestingly, 
sustained intracellular calcium disturbances are thought to be the proximal causes of aging and neurodegenerative disorders. The involvement of calcium in the pathogenesis of $\mathrm{AD}$ has been suggested long time ago by Khachaturian (Khachaturian, 1989). Since then increasing lines of evidence report that calcium disturbance is a factor contributing to the early development of Alzheimer's disease before the onset of cognitive decline, senile plaques, and neurofibrillary tangles (Bezprozvanny and Mattson, 2008; Bojarski et al., 2008) and that presenilins (PS) are involved in the calcium dysregulation observed in AD models. Indeed, mutations in the PS genes, that are responsible for early aggressive forms of familial AD (FAD; Campion et al., 1995), alter the cleavage of amyloid precursor protein and the production of the A $\beta$ peptide (Duff et al., 1996) but also disrupt intracellular calcium homeostasis (LaFerla, 2002). This link between PS mutations and $\mathrm{Ca}^{2+}$ dysregulation was initially discovered in fibroblasts from FAD patients (Ito et al., 1994) and later in neuronal and non-neuronal cells of transgenic mice model of FAD (LaFerla, 2002; Smith et al., 2005; Stutzmann et al., 2006).

PS mutations may affect endoplasmic reticulum (ER) calcium dynamics in multiple ways. After cell activation, $\mathrm{Ca}^{2+}$ is released from ER in a pattern specific for time, space, and dynamics (Berridge et al., 2000) through 2 main types of $\mathrm{Ca}^{2+}$ release channels called inositol 1,4,5-trisphosphate-activated receptor and ryanodine-sensitive receptor (RyR). $\mathrm{Ca}^{2+}$ releases result in depletion of ER $\mathrm{Ca}^{2+}$ stores, which are replenished by $\mathrm{Ca}^{2+}$ influx via channels activated by the depletion of the $\mathrm{Ca}^{2+}$ stores (called CCE for capacitive $\mathrm{Ca}^{2+}$ entry). The entering $\mathrm{Ca}^{2+}$ is then stored in the ER by sarco-endoplasmic reticulum calcium ATPases (SERCA). Overexpression of mutated PS1 has been shown to accelerate SERCA pump activity while PS knock-out decreases SERCA activity (Green et al., 2008; Jin et al., 2010). However, FAD-linked PS variants also enhance the expression and activities of $\mathrm{RyR} \mathrm{Ca}^{2+}$ release channels (Chan et al., 2000; Smith et al., 2005; Stutzmann et al., 2006), enhance the gating of 1,4,5-trisphosphate-activated receptor $\mathrm{Ca}^{2+}$ release channel resulting in impaired mitochondrial function (Toglia et al., 2016) and attenuate CCE (Herms et al., 2003; Leissring et al., 2000; Smith et al., 2002). In addition, depending on mutations PS1 may function as a calcium leak channel on the ER (Shilling et al., 2012; Somavarapu and Kepp, 2016; Tu et al., 2006).

Although the fine tune of $\mathrm{Ca}^{2+}$ signals is critical for contraction and relaxation of SMC which may be impaired in $A D$, there is no study to date on the disturbance of $\mathrm{Ca}^{2+}$ signals by PS mutations in VSMC. Here, we addressed the question of how the PS1dE9 mutation affects $\mathrm{Ca}^{2+}$ signaling and contractile the properties of mouse cerebral arteries. We challenged non-transgenic (NT) and PS1dE9 cerebral arteries with caffeine, thapsigargin, and cyclopiazonic acid (CPA), and we show that the vascular reactivity and specific $\mathrm{Ca}^{2+}$ signaling mechanisms are affected by the PS1dE9 mutation.

\section{Material and methods}

\subsection{Transgenic mice}

Male mice of the C57Bl/6J strain and of the transgenic PS1dE9 strain (PSEN1dE9: C57BL6 background from Jackson Laboratory) were used at the age of $8-10$ months. We chose PS1dE9 mice because they do not develop canonical amyloid pathology, providing a model with which to examine the contribution of the PS mutant in the regulation of $\mathrm{Ca}^{2+}$ signaling without being biased by the effects of elevated $A \beta$ or hyper-phosphorylated tau present in many AD mice models.

Progeny of cross-breeding male PS1dE9 mice with female C57Bl/ 6J mice were screened for transgenic expression by PCR using tail extracted DNA (directPCR lysis reagent, Viagen). The heterozygous males bearing one allele of the PS1dE9 mutation were used for the experiments. Mice used as control were aged-matched NT littermates. Mice were housed in a pathogen-free, temperature- and humidity-controlled facility with a 12 hours light/dark cycle. Mice were fed a standard laboratory diet and water ad libitum. All experiments conform to the European Directive on the Protection of Animals used for Scientific purposes.

\subsection{Cerebral vessel dissection}

Briefly, mice were killed by cervical dislocation. The first and second segments of the anterior, middle, and posterior cerebral arteries (ACA, MCA, and PCA respectively) were isolated and collected in phosphate-buffered solution (PBS). The vessels were cleaned by micro-dissection leading to meninx removal under a microscope. Blood vessels were then prepared for total RNA extraction, protein extraction, or fixed in PFA (4\%) for immunofluorescent staining.

\section{3. $R T-P C R$}

Total RNA was extracted from blood vessel tissues with Masterpure kit (Epicentre Biotechnologies) and used as template for RTPCR. The reverse transcription (RT) reaction was performed using Sensiscript RT kit (Qiagen). The polymerase chain reaction (PCR) was performed with 1- $\mu$ g cDNA, 1.25 unit of HotStartTaq DNA polymerase (Qiagen), $1 \mu \mathrm{M}$ of each primer, and $200 \mu \mathrm{M}$ of mixed deoxynucleotide triphosphates, in a final volume of $25 \mu \mathrm{L}$. Amplification products were separated by electrophoresis (2\% agarose gel) and visualized by ethidium bromide staining.

The primer pair allowing identification of human PS1 exon 9 was already published (Crook et al., 1998) and produces an amplicon of 599 bp. The nucleotide sequences of sense (s) and antisense (as) primers and the length of the expected PCR products (in parentheses) allowing identification of mouse PS1 and PS2 were: PS1(s) CTCgCCATTTTCAAgAAAgC, PS1(as) gggCTTgCTCTCTgTTTTTg (201 bp), and PS2(s) CTggTgCgCCCTTTCAT, PS2(as) TCCCCAACCTgCTCCAC (367 bp).

\subsection{Quantitative $P C R$}

As for classical PCR, the MasterPure kit (Epicentre) was used to isolate total RNA from cerebral arteries. RNA integrity and purity were verified by using RNA HighSens Analysis Kit (Experion, BioRad), and the concentration of RNA was measured with spectrophotometry (NanoDrop Technologies). RT reaction was carried out using the Sensiscript RT kit (Qiagen). Obtained cDNA were amplified using the primers designed with primer3 software (listed in the Table 1 of Supplementary Materials). The annealing temperature was determined with the gradient function of the CFX96 thermocycler (Bio-Rad), and the absence of primer dimerization was verified. The quantitative real-time PCR experiments were performed with the SYBR green PCR Master Mix (Bio-Rad) in the CFX96.

The specificity of the amplification products was confirmed by melting curve analysis. All samples were analyzed in duplicates. PCR efficiency was calculated from the slope of the standard curve. Gene expression levels were calculated using the $\Delta \Delta \mathrm{Ct}$ method normalized by 2 reference genes. The optimal number and choice of reference genes have been experimentally determined by the GeNorm method (Vandesompele et al., 2002) indicating the most stable reference genes in our experimental conditions (GAPDH, $\mathrm{BMG}$ ). In this experiment, we have used anterior, middle, and posterior cerebral arteries (ACA, MCA, and PCA) from 10 WT mice and 10 PS1dE9 mice. One to 3 samples were excluded from the statistical analysis based on poor RNA quality and outliers detection by the Grubb's and ROUT methods (GraphPad Prism). 
Table 1

Sequences and annealing temperatures of the primers used in qPCR for studying the expressions of SERCAs and RYRs

\begin{tabular}{|c|c|c|c|}
\hline \multicolumn{4}{|l|}{ Housekeeping genes } \\
\hline \multirow[t]{2}{*}{ BMG } & sens & CCTGGTCTTTCTGGTGCTTG & $60{ }^{\circ} \mathrm{C}$ \\
\hline & anti-sens & TATGTTCGGCTTCCCATTCT & 40 cycles \\
\hline \multirow[t]{2}{*}{ GAPDH } & sens & AACTTTGGCATTGTGGAAGG & $60^{\circ} \mathrm{C}$ \\
\hline & anti-sens & ACACATTGGGGGTAGGAACA & 40 cycles \\
\hline \multicolumn{4}{|l|}{ Target genes } \\
\hline \multirow[t]{2}{*}{ RYR1 } & sens & CCGGCGATGAATATGAACTT & $60{ }^{\circ} \mathrm{C}$ \\
\hline & anti-sens & TGATAGCCAGCAGAATGACG & 50 cycles \\
\hline \multirow[t]{2}{*}{ RYR2 } & sens & CATGGACAGCTTCCCCTGAA & $60{ }^{\circ} \mathrm{C}$ \\
\hline & anti-sens & GTGTGACTGCCGTGCTTGG & 50 cycles \\
\hline \multirow[t]{2}{*}{ RYR3 } & sens & CTGGCCATCATTCAAGGTCT & $60^{\circ} \mathrm{C}$ \\
\hline & anti-sens & GTCTCCATGTCTTCCCGTA & 50 cycles \\
\hline \multirow[t]{2}{*}{ SERCA2a } & sens & TCATGGATGAGACGCTCAAG & $60{ }^{\circ} \mathrm{C}$ \\
\hline & anti-sens & AGGGAGCAGGAAGATTTGGT & 40 cycles \\
\hline \multirow[t]{2}{*}{ SERCA2b } & sens & TTGGGTTTCCTGAGGCTTTA & $61{ }^{\circ} \mathrm{C}$ \\
\hline & anti-sens & GTCCAGGTCTGGAGGATTGA & 45 cycles \\
\hline \multirow[t]{2}{*}{ SERCA3 } & sens & TCTCGAATCGTGGAGAACCT & $60{ }^{\circ} \mathrm{C}$ \\
\hline & anti-sens & CCGATCTCTGCCTTCTTCAG & 45 cycles \\
\hline \multirow[t]{2}{*}{ phospholamban (PLB) } & sens & CGAAGCCAAGGTCTCCTAAA & $60{ }^{\circ} \mathrm{C}$ \\
\hline & anti-sens & TAGCCGAGCGAGTGAGGTAT & 40 cycles \\
\hline
\end{tabular}

\subsection{Western blot}

Cerebral blood vessels, peripheral blood vessels, or brain tissues were homogenized in PBS containing Triton $1 \%$, SDS $1 \%, 5-\mathrm{mM}$ EDTA, deoxycholate $1 \%$, and protease inhibitors (Sigma) by shaking with beads in the Minilys (Bertin). Proteins homogenates (100 $\mu \mathrm{g}$ for hippocampus and $150 \mu \mathrm{g}$ for blood vessels) were separated on acrylamide gel $4 \%-15 \%$ and transferred on nitrocellulose membranes. The membranes were heated for 15 minutes at $85^{\circ} \mathrm{C}$ in PBS buffer and then blocked with PBS, 5\% milk. PS1dE9 full length and PS1 Cter were immunoblotted with anti-PS1 (antibody registry: $A B \_10706356$ ) revealed with IRDye800 anti-rabbit antibody (antibody registry: AB_621843), anti-NeuN (antibody registry: AB_2298772) revealed with A680 anti-mouse antibody (antibody registry: $A B \_2535723$ ), and anti-GAPDH (antibody registry: AB_10615768) revealed with IRDye800 anti-chicken antibody (antibody registry: $A B \_1850023$ ).

\subsection{Immunofluorescent staining}

Isolated vessels were incubated in tri-sodium citrate buffer $10 \mathrm{mM}$, pH 6 and heated in a microwave (900W) for 20s for antigen retrieval. Primary antibodies were diluted 1:200 in phosphate buffer (PB: $0.1-\mathrm{M} \mathrm{NaH} \mathrm{PO}_{4}$ and $0.1-\mathrm{M} \mathrm{Na}_{2} \mathrm{HPO}_{4}$ ), donkey serum $2 \%$, triton $0.2 \%$, BSA $0.1 \%$, and incubated overnight at $4{ }^{\circ} \mathrm{C}$. Anti-PS1 (antibody registry: AB_2170605) and anti-PS2 (antibody registry: AB_325093) were from Thermo Scientific. Anti-MLC2 (myosine light chain 2 specific of smooth muscle, antibody registry: AB_2148039) was from Clinisciences. Anti-smoothelin (antibody registry: AB_2193677) was from Santa Cruz. AntiNeuN (antibody registry: AB_2149209) was from Millipore. AntiGFAP (antibody registry: AB_2532994) was from Thermo Fischer. Secondary antibodies (from Clinisciences) were incubated 2 hours at room temperature and washed 3 times. Slices and vessels are mounted in Vectashield hard-set or Fluoromount and observed with a confocal microscope (LEICA SP5) or macroscope (LEICA LSI).

\subsection{Preparation of cerebral arteries and $\mathrm{Ca}^{2+}$ dye loading of smooth muscle cells}

Animals were killed by cervical dislocation, and cerebral blood vessels were dissected from mice. Anterior and middle cerebral arteries (ACA and MCA respectively) were isolated and cleaned by micro-dissection to remove the meninges. Then, arteries were incubated in M199 medium (Invitrogen) with 2- $\mu$ M Fluo8acetoxymethyl ester (Interchim) for 15 minutes at $37{ }^{\circ} \mathrm{C}$ or $1-\mu \mathrm{M}$ Fura2-AM for 20 minutes at $37{ }^{\circ} \mathrm{C}$, washed with physiological solution pre-warmed at $25{ }^{\circ} \mathrm{C}$, and kept at room temperature during 20 minutes before starting experiments. Fluo5Nacetoxymethyl ester (Invitrogen) was loaded for 2 hours at 37 ${ }^{\circ} \mathrm{C}$, washed with physiological solution pre-warmed at $25^{\circ} \mathrm{C}$, and kept at room temperature during 30 minutes before starting experiments as previously described (Brochet et al., 2005). Blood vessels were used within the 6 hours from isolation in a physiological solution containing: $125-\mathrm{mM} \mathrm{NaCl}, 5.6-\mathrm{mM} \mathrm{KCl}, 1-\mathrm{mM}$ $\mathrm{MgCl}_{2}, 2-\mathrm{mM} \mathrm{CaCl} 2,8-\mathrm{mM}$ HEPES, and 11-mM glucose, PH 7.4; or in $\mathrm{Ca}^{2+}$-free solution where $\mathrm{CaCl}_{2}$ was omitted and EGTA was added to the physiological solution (0.5-mM EGTA 30 seconds before agonist and 10-mM EGTA during agonist application). In these preparations, only SMCs are stained with Fluo8: the stained cells are transversal cells perpendicular to the axis of the vessel, they contract on stimulation, and they are positively stained by MLC2 or smoothelin.

\section{8. $\mathrm{Ca}^{2+}$ measurements}

Measurement of $\mathrm{Ca}^{2+}$ signals in smooth muscle myocytes was described previously (Dabertrand et al., 2006; Le Blanc et al., 2004). Spontaneous $\mathrm{Ca}^{2+}$ activity and agonist-evoked $\mathrm{Ca}^{2+}$ responses were measured by excitation of Fluo8 or Fluo5N at $488 \mathrm{~nm}$ and collection of the fluorescence emitted at wavelengths greater than $515 \mathrm{~nm}$. The value of fluorescence of each pixel was divided by the fluorescence of the rest-level fluorescence of the same pixel (F0) and reported as fluorescence ratios F/FO in a timecourse graph. Spontaneous $\mathrm{Ca}^{2+}$ sparks, caffeine-, CPA- and thapsigargin-induced $\mathrm{Ca}^{2+}$ responses were recorded with the confocal Leica SP5 allowing images acquisition at a rate of 6 images per second. $\mathrm{Ca}^{2+}$ responses were expressed as the change of the area under the curve measured above the basal $\mathrm{Ca}^{2+}$ level. Decay times are expressed as $t_{1 / 2}$ values, corresponding to the time taken for a response to decline to $50 \%$ of its peak value. Time course of CCE were measured every 10s. Data are expressed as means $\pm \mathrm{SEM}$; the number of cells is indicated in parenthesis on the figures. Mean $\mathrm{Ca}^{2+}$ responses were calculated by averaging the responses of 10-15 cells per animal. Five animals (i.e., 50-75 cells) per group were used for the statistical analysis.

\subsection{Ex-vivo contraction measurements}

We used an automatic method developed by Levet and Sibarita (IINS, UMR5297, Bordeaux) to measure contraction of the vessels by multistep analysis of the $\mathrm{Ca}^{2+}$ images. Briefly, this method uses wavelet's segmentation of the $\mathrm{Ca}^{2+}$ images of the vessel and reconstitution of the vessel's shape by driving snakes which continuously identify the whole vessel at each time point allowing the final contraction computation. This 2-step analysis prevents from motion artifacts that might obscure accurate measurements of dynamic parameter of contraction. Maximal cell contraction was evaluated by the ratio between the resting cell length (before caffeine application) and the minimal cell length observed during caffeine application at the same vessel section. Mean vessel diameter was calculated by averaging the length of 5 cells per animal. Five animals (i.e., 25 cells) per group were used for the statistical analysis. The contraction is expressed as percentage values of the basal diameter for each group. 


\subsection{In vivo contraction measurements}

Mice were anesthetized (IP injection of a ketamine/xylazine cocktail, 100 and $50 \mathrm{mg} / \mathrm{kg}$, respectively) and placed under a stereotaxic apparatus. A cranial window $(3 \times 3 \mathrm{~mm})$ was prepared using a dental drill to allow access to MCA collaterals. Cerebral arteries were imaged with a real-time, fiber-optic-based confocal laser scanning microscope (Cellvizio Lab 488, Mauna Kea Technologies). The Z1800 probe was maintained on the surface of the brain allowing imaging of a field of $0.28 \mathrm{~mm}^{2}$ with $70-\mu \mathrm{m}$ optical section and $100 \mu \mathrm{m}$ working distance at a rate of 12 images per second. After the administration of FITC-Dextran (FD-150S, $0.3 \mathrm{~mL}, 75 \mathrm{mg} /$ $\mathrm{kg}$ ) via the tail vein, FITC-Dextran was excited at $488 \mathrm{~nm}$ and its emission was recorded before, during, and after injection of $20 \mu \mathrm{g} /$ $\mathrm{kg}$ phenylephrine for 10 seconds. At the end of the protocol, mice were euthanized by pentobarbital injection $(180 \mathrm{mg} / \mathrm{kg})$. This protocol was described in a submission (A50120140) approved by the Ethics Committee of Bordeaux. Blood vessel diameters were measured directly on images with the ImageCell software (Mauna Kea Technologies). All arteries displaying a diameter between 15 and $30 \mu \mathrm{m}$ were analyzed. Maximal vessel contraction was evaluated by the ratio between the resting artery diameter (before agonist application) and the minimal diameter observed during agonist application at the same section level. Mean vessel diameter was calculated by averaging the length of 3 measures $\times 4$ vessels per animal. Four animals (i.e., 16 vessels) per group were used for the statistical analysis. The contraction is expressed as percentage values of the basal diameter for each group.

\subsection{Statistical analysis}

For the calcium and contraction studies, significance between NT and PS1dE9 was tested by 2-tailed Student $t$ test (GraphPad software). For the RT-PCR, analysis of variance (2-way ANOVA + Bonferroni's post hoc test) as well as Multiple $t$ test were used to study the data (GraphPad software). Results are expressed as mean \pm SEM. $p$ values $<0.05,<0.001$, and $<0.0001$ were respectively considered as statistically significant, highly significant, and extremely significant.

\section{Results}

\subsection{Expression of the endogenous PS1 and the human PS1dE9 mutation in cerebral arteries}

We first checked the expression of PS1 in cerebral blood vessels isolated from $\mathrm{C} 57 \mathrm{Bl} / 6 \mathrm{~J}$ mice. RT-PCR reveals the expression of PS1 transcripts in all cerebral arteries tested: ACA, MCA, and PCA (Fig. 1A). We confirmed the presence of corresponding PS proteins in cerebral arteries by fluorescent immunostaining (Fig. 1B), whereas control experiments with secondary antibody alone showed no immunoreactivity (data not shown). PS1 has also been found in peripheral vessels (see Supplementary Material Fig. S2).

We combined PS1 and MLC2 immunostaining to identify PS1 expression within the SMC layer of the vessel wall. Co-immunostaining of MLC2 and PS1 proves the expression of PS1 in SMCs of cerebral pial arteries and peripheral vessels and shows that the subcellular localization of the 2 proteins differs since the 2 dyes do not overlap (Figs. $1 \mathrm{~B}$ and S2).

To determine if the human PS1dE9 mutation was also present in the cerebral vasculature of the transgenic mice, we performed RT-PCR with primers designed to anneal to exon 5 and exon 10 of human PS1 sequence (Crook et al., 1998). A truncated PS1 amplicon of $599 \mathrm{bp}$, corresponding to the deletion of exon 9, was found in cerebral arteries from PS1dE9 mice but not in cerebral arteries from
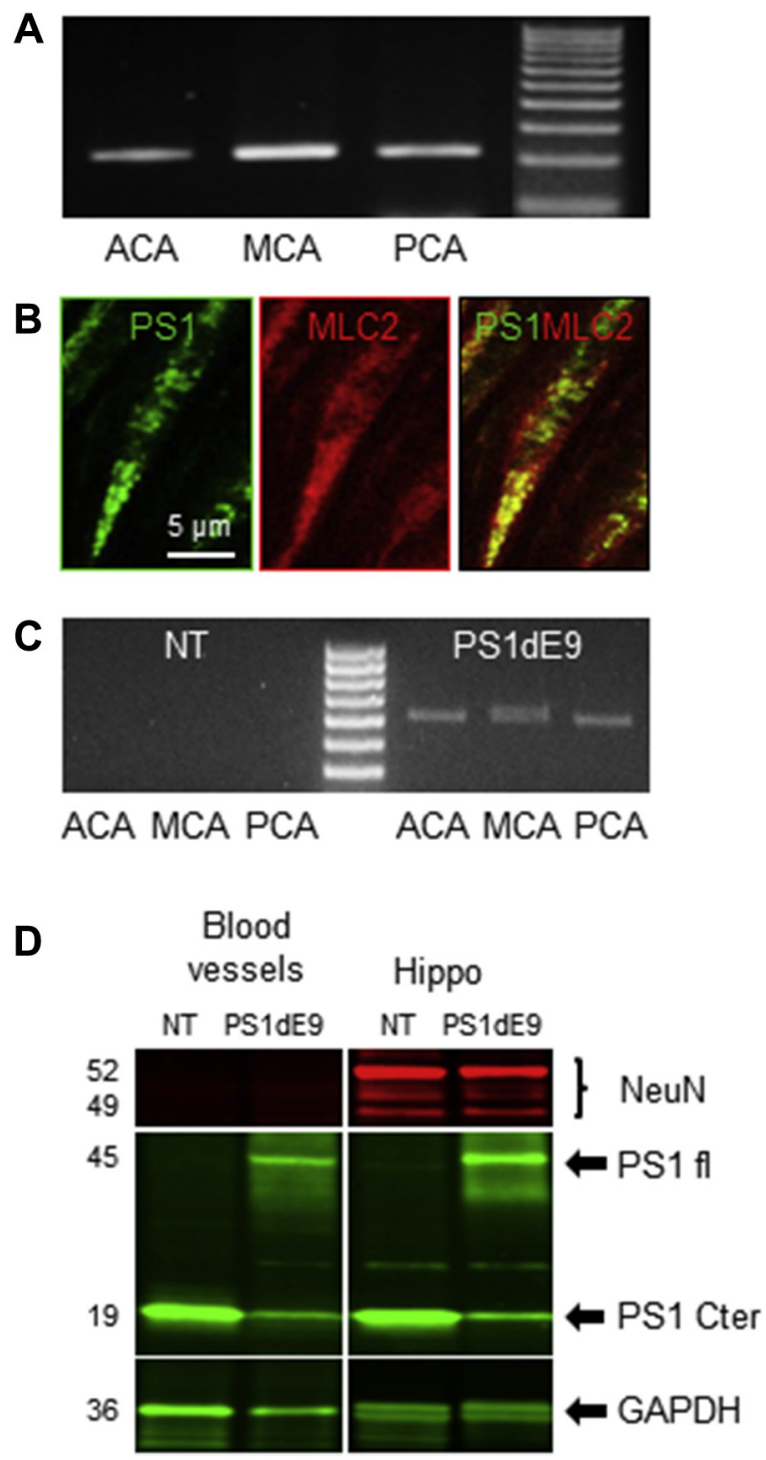

Fig. 1. Expression of PS1 and PS1dE9 mutation in cerebral arteries. (A) RT-PCR showing the expression of mouse PS1 in cerebral vessels of mouse. ACA, MCA, PCA: anterior, middle, posterior cerebral artery; DNA ladder (1000-100bp). (B) PS1 immunoreactivity in mouse ACA shown by fluorescent immunostaining of anti-PS1 revealed by A488conjugated secondary antibody. Co-immunostaining of MLC2 (revealed by A546conjugated secondary antibody) and PS (A488) reveals the expression of PS in the smooth muscle myocytes of cerebral arteries. (C) RT-PCR performed with primers designed to anneal to the human PS1dE9 reveal a truncated PS1 amplicon of 599 bp only in cerebral arteries from PS1dE9 mice. (D) Western blot expression of PS1 in cerebral blood vessels and hippocampus of NT and PS1dE9 mice. Proteins homogenates ( $100 \mu \mathrm{g}$ for hippocampus and $150 \mu \mathrm{g}$ for blood vessels) were separated on acrylamide gel and transferred on nitrocellulose membranes. PS1 full-length proteins and Cter fragments were revealed by immunoblotting with anti-PS1. GAPDH and NeuN were stained on the same membrane to control protein charge and purity of the preparations. Molecular weights of the peptides are indicated on the right of the Western blot Abbreviations: ER, endoplasmic reticulum; MLC2, myosine light chain 2; PS1, presenilin 1; PS1dE9, deletion of exon 9 of PS1; VSMCs, vascular smooth muscle cells.

NT mice (Fig. 1C) showing that in PS1dE9, cerebral blood vessels express the mutated PS1. Because these RT-PCR experiment showing that PS1dE9 mutant is expressed in cerebral arteries could be biased by the contamination by neurons or astrocytes in our preparation, we verified (1) that our isolated vessel preparations were free of neurons and (2) that the mutant PS1dE9 peptides were produced in blood vessels that did not express NeuN. 
A

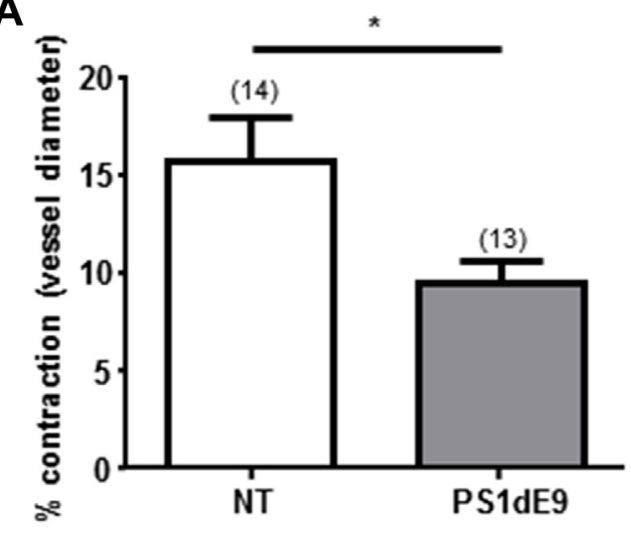

B

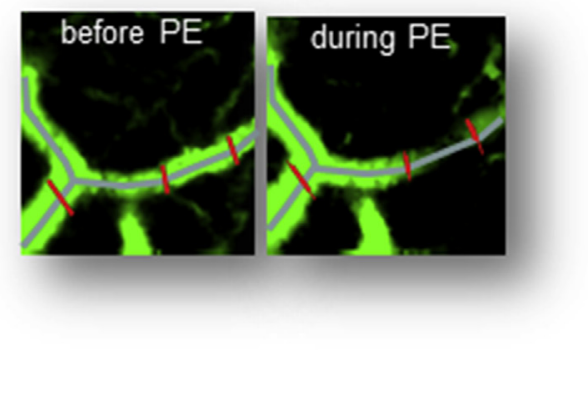

$\mathbf{D}$

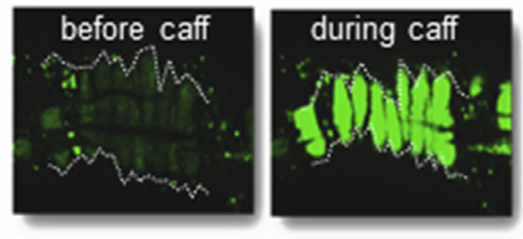

E

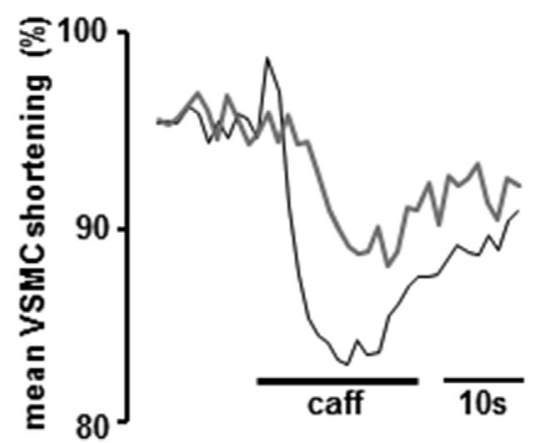

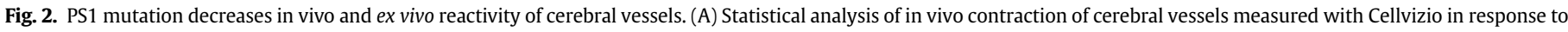

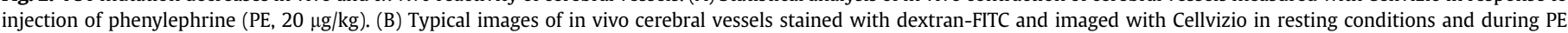

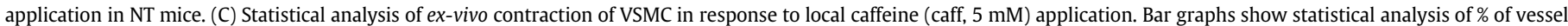

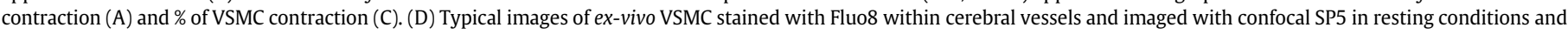

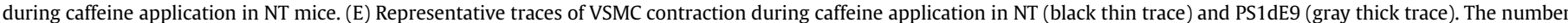

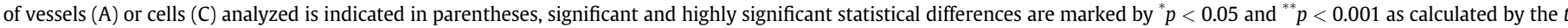
test. Abbreviations: ER, endoplasmic reticulum; PS1, presenilin 1; PS1dE9, deletion of exon 9 of PS1; VSMCs, vascular smooth muscle cells.

The cerebral arteries we used in calcium experiments or RT-PCR experiments are free of neurons as revealed by co-immunostaining of smoothelin and NeuN in these preparations. These immunostainings were performed at the same time and with the same solutions than the ones performed in brain slices displaying both NeuN and smoothelin stainings (Suppl Fig. S1). Only few astrocytic endfeet (without astrocyte cell body) are found in isolated blood vessels stained with smoothelin and GFAP (Suppl Fig. S1).

In addition, we did Western blot analyses of PS1 and NeuN expression in blood vessels and hippocampus of WT and PS1dE9 mice (Fig. 1D). These results show that in NT mice C-terminal fragments of PS1 are highly expressed, whereas the full length protein is not found in blood vessels or in hippocampus attesting a high endoproteolytic activity of PS1. In contrast, PS1dE9 mutants show the accumulation of the full length proteins and decrease of the proteolytic fragments in both blood vessels and hippocampus as expected for PS1dE9 mutant lacking endoproteolysis activity. The GAPDH staining attests that similar quantities of proteins have been charged in the electrophoresis gels for NT and PS1dE9. Our results are consistent with the fact that PS1dE9 is not a substrate for endoproteolysis (Borchelt et al., 1996; Thinakaran et al., 1996) and show that of the PS1dE9 mutant is expressed in both blood vessels and hippocampus. The NeuN protein was not detected in blood vessels although it was largely stained in hippocampus ruling out a possible neuronal contamination of blood vessel preparations. Together these results prove that PS1 protein is expressed in the SMCs and that the PS1 transgene (PS1dE9) under the MoPrP.Xho promoter is expressed in blood vessels. The isolated cerebral blood vessels preparation used in this manuscript do not express neurons or astrocytes.

\subsection{Effect of the PS1dE9 mutation on the contractile responses in cerebral arteries}

We first measured the contractile response of cerebral arteries activated in vivo by IV injection of phenylephrine (PE, $20 \mu \mathrm{g} / \mathrm{kg}$, Fig. 2B). As illustrated in Fig. 2A, we found a significant reduction in the reactivity of 
A

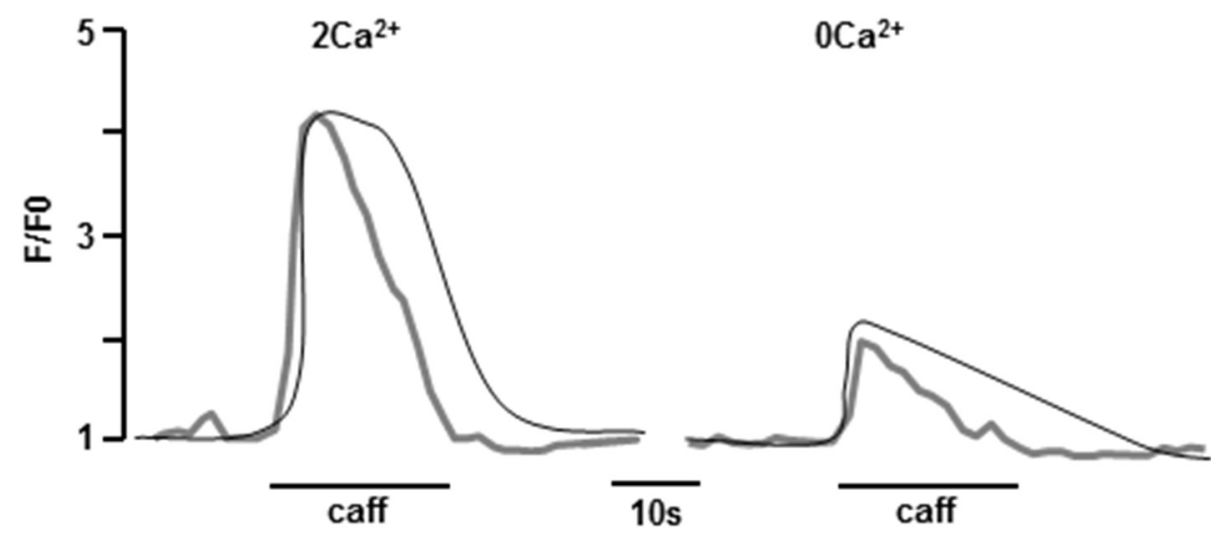

B

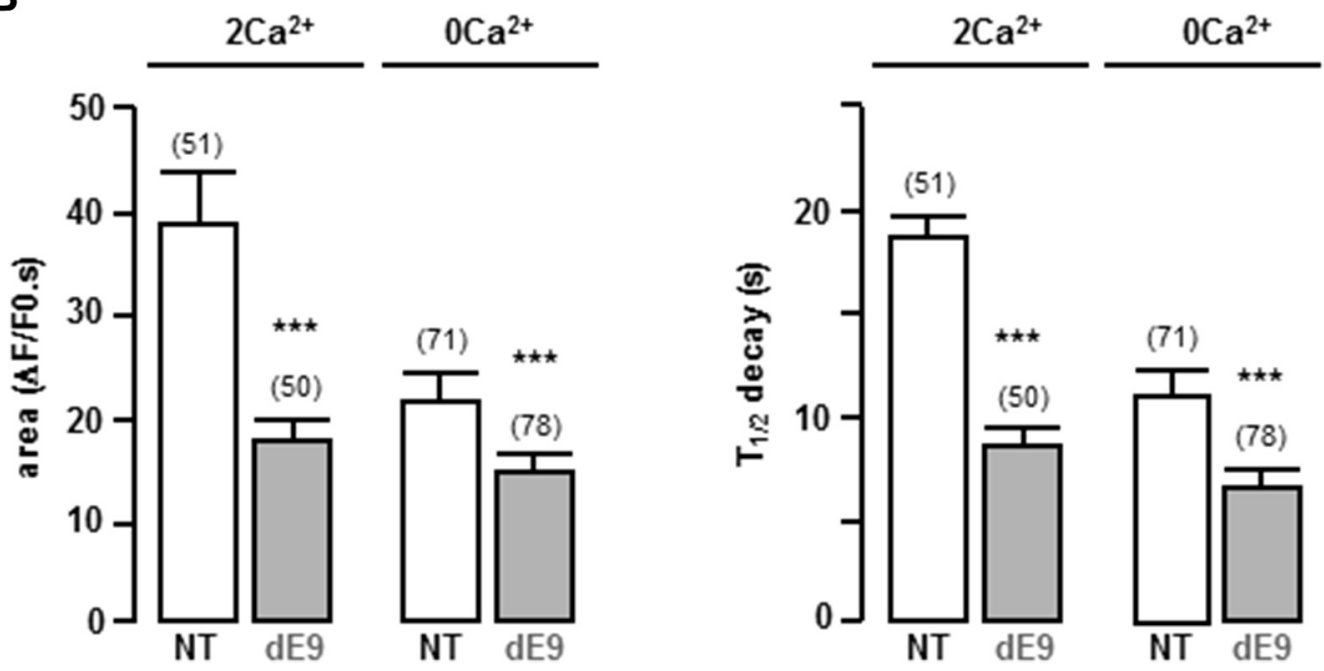

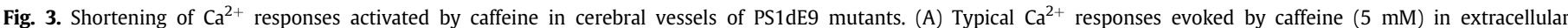

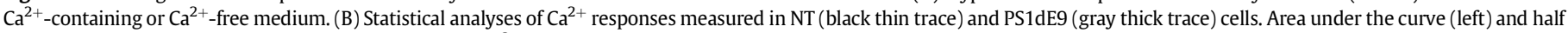

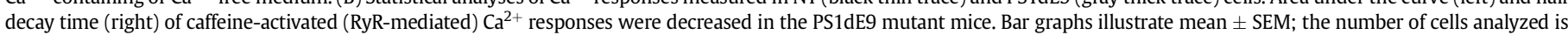
indicated in parentheses; ${ }^{* * *}$ indicate $p<0.0001$ calculated by $t$ test. Abbreviations: PS1dE9, deletion of exon 9 of PS1; SEM, standard error of the mean.

PS1dE9 arteries compared with NT arteries (15.77\% contraction in WT vs. 9.45\% contraction in PS1dE9, $p=0.0186$ ). These results suggest a reduction in contraction capacity of cerebral vessels in PS1dE9 mice.

We completed this result by further exploring the reactivity of cerebral vessels ex-vivo when they were activated by caffeine (5 mM, Fig. 2D and E). We and others have shown that phenylpehrine-induced $\mathrm{Ca}^{2+}$ signals are relayed by $\mathrm{Ca}^{2+}$-induced $\mathrm{Ca}^{2+}$ release through RyR in VSMCs (Boittin et al., 1999). Since caffeine is a direct activator of RyR, we designed experiments to measure both caffeine-activated $\mathrm{Ca}^{2+}$ responses and contractions on cerebral vessels. Images were analyzed to measure cell shortening induced by caffeine. The intrinsic capacity of cerebral vessels to answer to a stimulus was reduced in PS1dE9 versus NT as shown in Fig. 2C (18.34\% contraction in NT vs. $13.42 \%$ contraction in PS1dE9, $p=0.0002)$. Regulation of smooth muscle contraction through neuronal/astrocytic mutant PS1dE9 is unlikely since we never observed any neuronal or astrocyte cell body in the isolated blood vessel preparations we used for contraction $/ \mathrm{Ca}^{2+}$ measurements (Suppl Fig. S1). These results suggest that vascular PS1dE9 intrinsically modifies the reactivity of the SMCs of blood vessels when they are stimulated by an agonist.

\subsection{Effect of the PS1dE9 mutation on the caffeine-activated $\mathrm{Ca}^{2+}$ responses in cerebral arteries}

Since the fine tuning of $\mathrm{Ca}^{2+}$ signals is critical for contraction and relaxation of VSMC (Mironneau et al., 1996; Nelson et al., 1995), we hypothesized that the alteration of the regulation of cytoplasmic $\mathrm{Ca}^{2+}$ levels in PS1dE9 could affect the reactivity of cerebral vessels. Therefore, we studied whether the $\mathrm{Ca}^{2+}$ signals are altered in VSMC of PS1dE9 mice. Based on studies showing that RYRs control both InsP3- and $\mathrm{Ca}^{2+}$-induced $\mathrm{Ca}^{2+}$ signals in VSMCs (Boittin et al., 1998, 1999; Coussin et al., 2000) and that PS interact with RYRs to influence their activity (Hayrapetyan et al., 2008; Payne et al., 2013; Rybalchenko et al., 2008), we focused our investigations on the effect of the PS1dE9 mutation on the caffeine-activated RYR-mediated $\mathrm{Ca}^{2+}$ signals. The amplitude (peak) of caffeine-induced $\mathrm{Ca}^{2+}$ responses was not significantly different in NT and PS1dE9 vascular myocytes, either in the presence (mean $\Delta \mathrm{F} / \mathrm{FO}=4.26$ in NT and 3.74 in PS1dE9, $p=$ 0.3459 ) or in the absence of extracellular $\mathrm{Ca}^{2+}$ (mean $\Delta \mathrm{F} / \mathrm{F} 0=$ 2.53 in NT and 2.22 in PS1dE9, $p=0.1352$; Fig. 3A). However, our data show that the PS1dE9 mutation leads to lessen the RYR-Ca ${ }^{2+}$ 
release in VSMCs of cerebral arteries. Indeed, the area under the curve $\left(-54.6 \%\right.$ in $2 \mathrm{mM} \mathrm{Ca}^{2+} ; p<0.0001$ and $-33.8 \%$ in $0 \mathrm{mM}$ $\left.\mathrm{Ca}^{2+} ; p<0.0001\right)$ and the $\mathrm{t}_{1 / 2}$ decay time $\left(-49.7 \%\right.$ in $2 \mathrm{mM} \mathrm{Ca}^{2+}$; $p<0.0001$ and $-37.9 \%$ in $\left.0 \mathrm{mM} \mathrm{Ca}^{2+} ; p<0.0001\right)$ were significantly decreased (Fig. 3B) in VSMC from PS1dE9 mice compared with WT mice. The mechanism by which the caffeine-induced $\mathrm{Ca}^{2+}$ responses is lessen is: (1) independent on $\mathrm{Ca}^{2+}$ entry since it was also observed in the absence of extracellular $\mathrm{Ca}^{2+}$; (2) independent on triggering $\mathrm{Ca}^{2+}$ release by RyR activation since peak amplitude of caffeine-induced $\mathrm{Ca}^{2+}$ response is unchanged; and (3) rather due to mechanisms able to shorten of the $\mathrm{Ca}^{2+}$ release (Fig. 3A and B).

\subsection{Effect of the PS1dE9 mutation on RYR-mediated elementary $\mathrm{Ca}^{2+}$ signals}

We then focused on spontaneous $\mathrm{Ca}^{2+}$ sparks (Fig. 4A), which are elementary events resulting from the opening of few RYR channel organized in cluster (Macrez and Mironneau, 2004) and studied whether they were modified in the myocytes of PS1dE9 cerebral arteries. We found no change in $\mathrm{Ca}^{2+}$ sparks frequency or number of $\mathrm{Ca}^{2+}$ spark sites in PS1dE9 cells compared with NT cells (Fig. 4B). The percentage of cells displaying $\mathrm{Ca}^{2+}$ sparks was similar in PS1dE9 compared with NT arteries. The characteristics of the sparks (amplitude, full width at half maximal amplitude, half decay time) were the same in the 2 types of vessels (data not shown). These results suggest that spontaneous activity of RyR channels is not directly affected by the mutation of PS1.

\subsection{Effect of PS1dE9 mutation on capacitive $\mathrm{Ca}^{2+}$ entry and SERCA}

Since the mechanism by which the $\mathrm{Ca}^{2+}$ responses are lessen in PS1dE9 is due to mechanisms able to shortening the $\mathrm{Ca}^{2+}$ release rather than to inhibiting the release itself, we hypothesized that the decrease in caffeine-induced $\mathrm{Ca}^{2+}$ release was due to an increase of the $\mathrm{Ca}^{2+}$ re-uptake in the SR by the SERCA pumps. Indeed, disturbance of SERCA activity was shown in cellular models expressing PS1 mutations (Green et al., 2008). To evaluate how the SERCA pumps were involved in modification of the $\mathrm{Ca}^{2+}$ signaling in cerebral blood vessels with PS1dE9 mutation, we used 2 different protocols.

The first protocol consisted of the activation of CCE by caffeine allowing the measurement of the entry of $\mathrm{Ca}^{2+}$ minus the storage of $\mathrm{Ca}^{2+}$ by SERCA during the re-admission of $\mathrm{Ca}^{2+}$. By applying 5-mM caffeine for 20s in the absence of extracellular $\mathrm{Ca}^{2+}$, the $\mathrm{Ca}^{2+}$ stored in the SR was completely released (no further caffeine responses could be obtained; data not shown) and we measured the CCE when $\mathrm{Ca}^{2+}$ was re-admitted in the external solution. The rise of $\left[\mathrm{Ca}^{2+}\right]_{i}$ after 120 seconds CCE was significantly higher $(p=0.0135)$ in NT cells (mean $\Delta \mathrm{F} / \mathrm{FO}=0.54 ; \mathrm{n}=59$ ) than in PS1dE9 cells (mean $\Delta \mathrm{F} / \mathrm{F} 0=0.23 ; \mathrm{n}=57$; Fig. $5 \mathrm{~A}$ and $\mathrm{B}$ ). This decreased CCE observed in PS1dE9 could be due to either a decreased $\mathrm{Ca}^{2+}$ entry or an increased $\mathrm{Ca}^{2+}$ pumping into the ER.

In the second protocol, to distinguish the CCE from the $\mathrm{Ca}^{2+}$ reuptake in the SR, we used thapsigargin to block the SERCA. This drug leads to emptying of the SR calcium stock and allows measurement of pure $\mathrm{Ca}^{2+}$ entry during $\mathrm{Ca}^{2+}$ re-admission. When CCE was measured during $\mathrm{Ca}^{2+}$ re-admission after store depletion by $10-\mu \mathrm{M}$ thapsigargin in $\mathrm{Ca}^{2+}$-free solution, there was no significant difference between CCE in NT cells and PS1dE9 cells (Fig. 5C and D). These data suggest that the difference observed with caffeineinduced CCE was mainly due to increased SERCA activity in PS1dE9 myocytes.

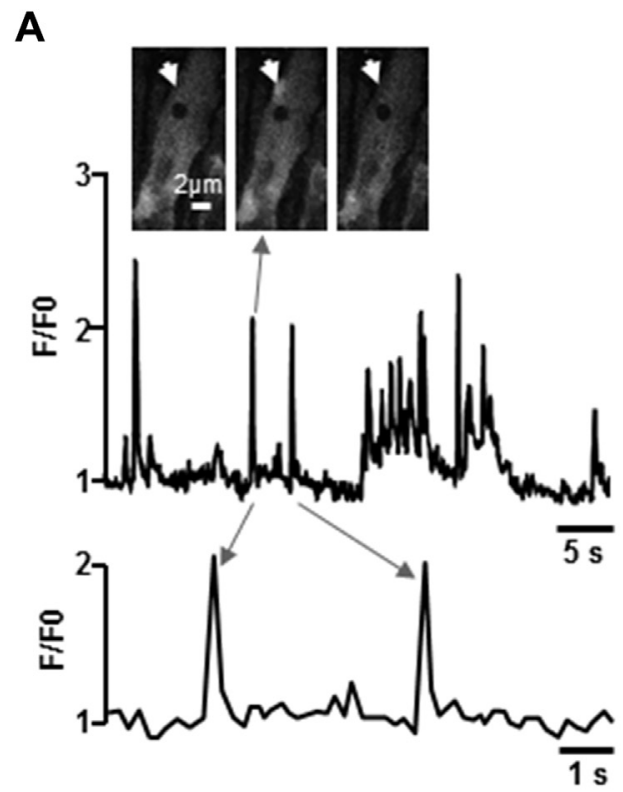

B

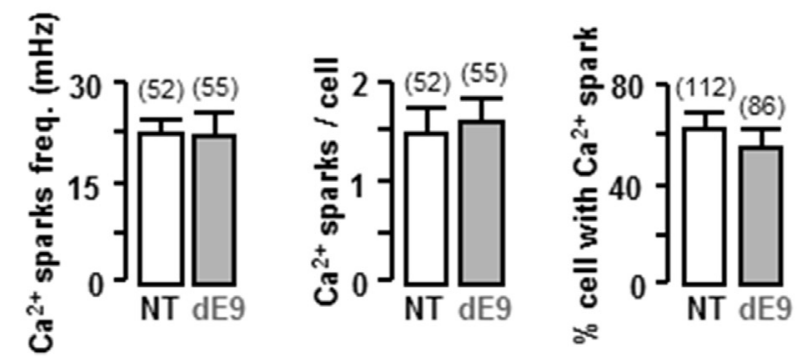

Fig. 4. No effect of the PS1dE9 mutation on spontaneous $\mathrm{Ca}^{2+}$ sparks. (A) Upper trace show time course of the $\mathrm{Ca}^{2+}$ signal that occurred in a region of 2 microns in diameter indicated by the arrow on the images of a myocyte of cerebral artery (inset); trace of spontaneous $\mathrm{Ca}^{2+}$ sparks was enlarged (lower trace). (B) Statistical analyses of spontaneous $\mathrm{Ca}^{2+}$ sparks in both NT and PS1dE9 cerebral arteries myocytes. Neither $\mathrm{Ca}^{2+}$ spark frequency (left) nor the number of $\mathrm{Ca}^{2+}$ spark site per cell (middle) nor the percentage of cell displaying $\mathrm{Ca}^{2+}$ sparks (right) are affected in the PS1dE9 mutant mice. Bar graphs illustrate mean \pm SEM; the number of cells analyzed is indicated in parentheses. Abbreviations: PS1dE9, deletion of exon 9 of PS1; SEM, standard error of the mean.

\subsection{Effect of PS1dE9 mutation on expression of SERCA and RYR in} cerebral vessels

Several studies showed that PS mutations modify RYRs expression and RyR-mediated $\mathrm{Ca}^{2+}$ release (Magi et al., 2016; Wu et al., 2013) and alter the function of the SERCA pump (Green et al., 2008). These results were mainly obtained in neurons or cell lines transfected with mutant PS. Here, we studied the expression of RyR1,2,3; SERCA2,3 isoforms and phospholamban (PLB, regulator of SERCA2; MacLennan and Kranias, 2003) in cerebral vessels from NT and PS1dE9 mice. SERCA1 was not studied because it is known to be expressed exclusively in skeletal muscle fibers. By RT-qPCR, we show that the expressions of SERCA3, PLB (Fig. 6A), and RyR3 (Fig. 6B) were significantly increased in PS1dE9, whereas the expression of other isoforms of proteins were unchanged. The increase in RyR3 is validated by 2-way ANOVA $(p=0.0008)$ and multiple $t$ test $(p=0.0016)$, whereas the increase in SERCA3 and PLB is not significant with 2-way ANOVA $(p=0.0562)$ but validated by multiple $t$ test ( $p=0.0098$ for SERCA3 and $p=0.0222$ for PLB). These results suggest that RyR3, SERCA3, and PLB may be involved 
A

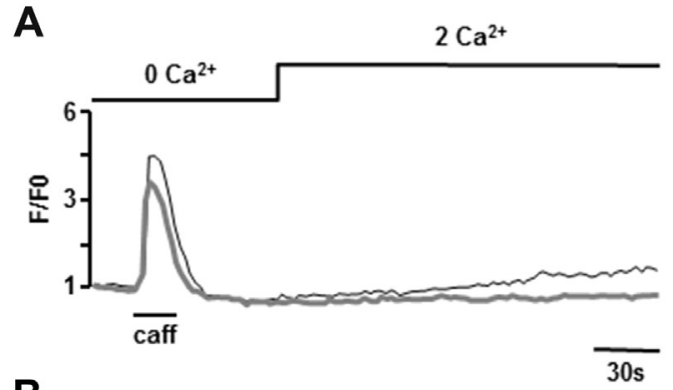

B
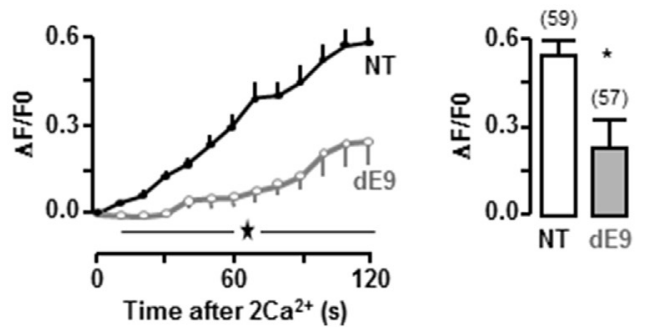

C

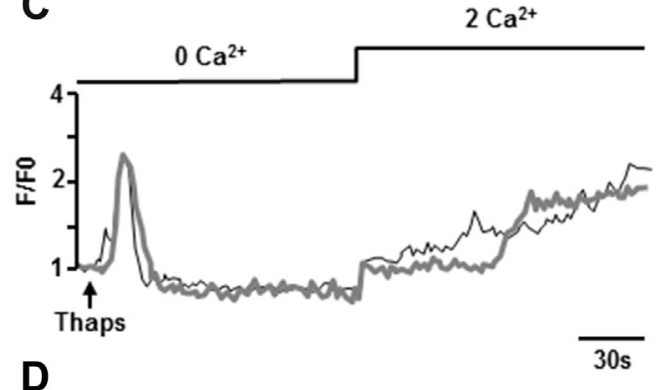

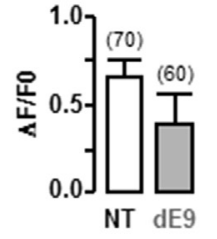

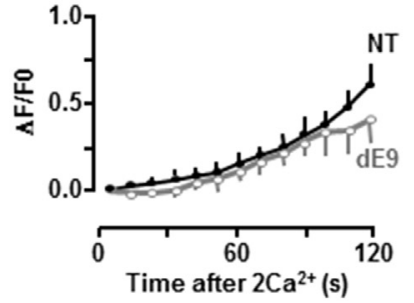

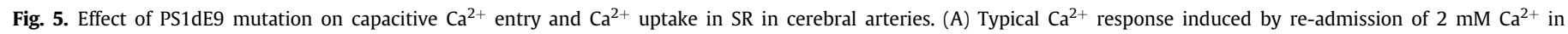

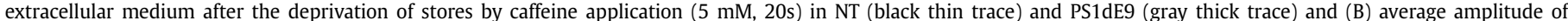

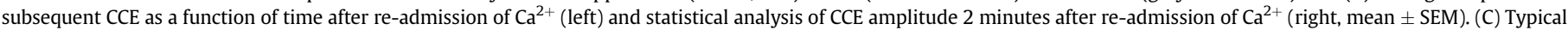

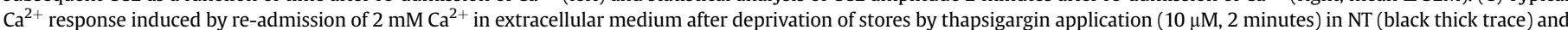

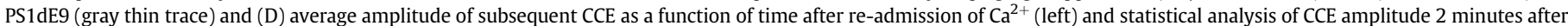

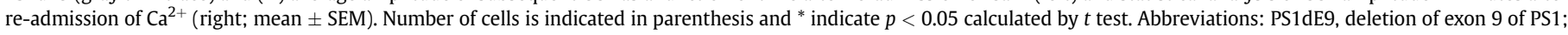
SEM, standard error of the mean.

in the shortening of $\mathrm{Ca}^{2+}$ responses and decreased the contraction of cerebral vessels.

\subsection{Blocking SERCA cancels the effect of PS1 mutation on caffeine-induced $\mathrm{Ca}^{2+}$ response}

To reveal the relative importance of increased $\mathrm{Ca}^{2+}$ re-uptake regarding the increase of RyR3 expression, we measured caffeineinduced $\mathrm{Ca}^{2+}$ responses when $1 \mu \mathrm{M}$ of CPA, a transient SERCA inhibitor, was co-applied with caffeine. In this experiment, the transient SERCA inhibitor CPA instead of the irreversible inhibitor Thapsigargin was used to maintain the content of the $\mathrm{Ca}^{2+}$ store. As shown in Fig. 7A, we noticed an increase in caffeine + CPA-induced $\mathrm{Ca}^{2+}$ responses in both cell types when compared with the application of caffeine only (cf Fig. 3). However, the caffeine + CPAinduced $\mathrm{Ca}^{2+}$ responses in $\mathrm{Ca}^{2+}$-containing and in $\mathrm{Ca}^{2+}$-free extracellular medium were not significantly different in NT and PS1dE9 myocytes (Fig. 7B). These results suggest that once the SERCAs are inhibited by CPA, the increased RyR3 expression does not alter $\mathrm{Ca}^{2+}$ signals in the mutant myocytes.

\section{Discussion}

In the present work, we assessed the expression of presenilins in the native cerebrovascular SMC and the presence of the mutation in cerebrovascular SMC of PS1dE9 transgenic mice. We described how this mutation modifies the $\mathrm{Ca}^{2+}$ signals and contraction in cerebral vessels thereby providing experimental evidences that vessel reactivity is affected trough $\mathrm{Ca}^{2+}$ dysregulation in PS1 mutant mice.

\subsection{PS expression and PS1dE9 mutation in vascular cells}

Although PS expression appears ubiquitous based on crude tissue analysis (Lee et al., 1996), there was no clear result to date on vascular expression of these proteins. Here, we proved the cerebrovascular expression of both PS transcripts and proteins by
RT-PCR, immunostaining, and Western blot in isolated cerebral and peripheral blood vessels. We then focused on SMC which are in charge of regulating the diameter of pial arteries and the blood supply to the penetrating arterioles and capillaries. The dual staining of MLC2 and PS reveal that PS1 and PS2 are expressed in cerebrovascular SMC. These results contrast with studies that found no in situ hybridization of PS1 cRNA probe and no immunostaining of PS1 in cerebral vessels (Elder et al., 1996; Gama Sosa et al., 2010). The difference between our results and these in situ findings might be explained by different mouse model used (neuron-specific promoters used for PS expression), the techniques (cRNA versus antibody, unmasking protocol used in our study) and the anti-PS antibodies used in the different immuno-labelings. Our results are in line with previous ones showing that PS have been found in many tissues (Rogaev et al., 1995), since vasculature is the only common structure to all organs, the "ubiquitous" expression profile of PS may also reflect a vascular expression of PS throughout the vascular tree. Our results showing the expression of PS in vascular SMCs are in agreement with data showing that PS-dependent amyloidogenic pathway is activated in cultured VSMC stressed by $\mathrm{H}_{2} \mathrm{O}_{2}$ (Coma et al., 2008), iron (Frackowiak et al., 2004) or by A $\beta$ (Davis-Salinas et al., 1995). Moreover, tissue-specific knockout of presenilins have identified the skin, vascular, and immune systems as very sensitive to loss of presenilin functions (McCarthy et al., 2009).

We then ensured that the PS1dE9 mice did express the truncated dE9 isoform of the human PS1 in cerebral vessels by using PCR primers previously published to amplify the dE9 mutant of human PS1 (Crook et al., 1998). Here, we showed that the PS1dE9 mutant is expressed in cerebral blood vessels. This result is further confirmed by Western blot experiments showing that the PS1dE9 mutant is expressed at the protein level in blood vessels that do not express NeuN. Together these results prove that PS1 protein is expressed in the SMCs and that the PS1 transgene (PS1dE9) under the MoPrP.Xho promoter is expressed in smooth muscle of blood vessels, which is in agreement with previous report showing that the prion promoter (MoPrP.Xho) used in the PS1dE9 transgene 
A

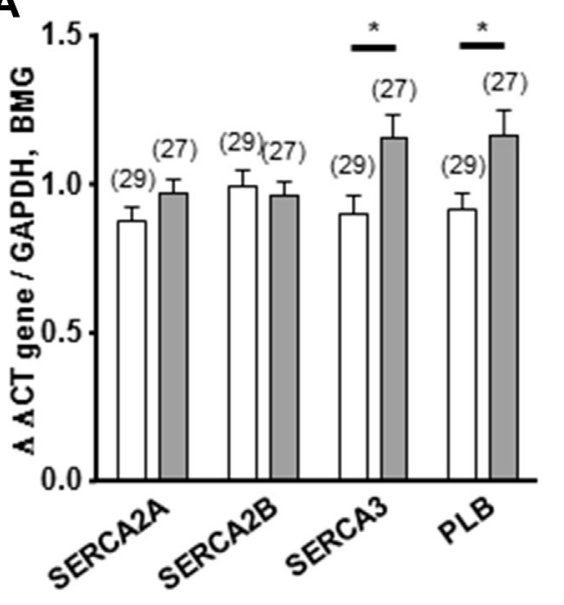

B

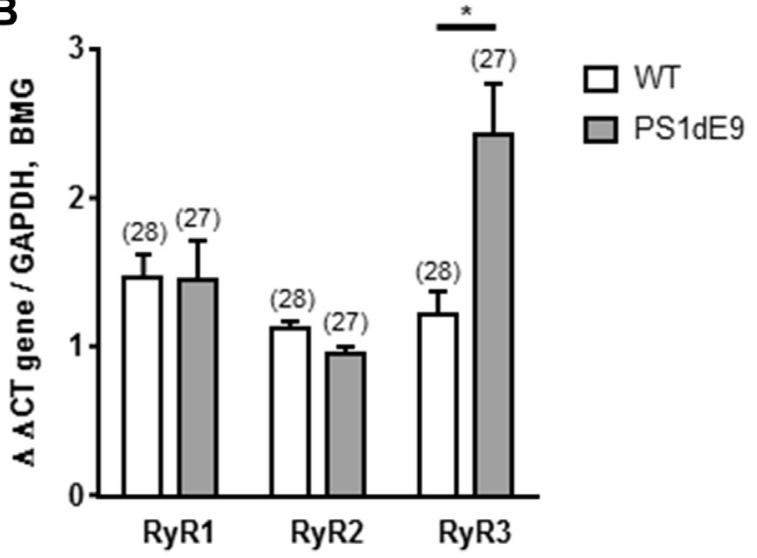

Fig. 6. Increased expression of SERCA3, PLB, and RyR3 in cerebral vessels of PS1 mutants. Statistical analyses of SERCA and PLB (A) and of RyR (B) expressions measured by RT-qPCR. Bar graphs illustrate mean \pm SEM; the number of vessels analyzed is indicated in parentheses; ${ }^{*}$ indicate significant differences $(p<0.05)$ calculated by multiple $t$ test. Abbreviations: PLB, phospholamban; PS1, presenilin 1; SEM, standard error of the mean.

provides relatively high levels of transgene-encoded polypeptides in brain but also in heart, kidney, and substantial expression in lung and liver.

Among several PS1 mutations transfected in HEK cells, the PS1dE9 mutation produced the greatest increase of the $A \beta 42 / A \beta 40$ ratio and atypical $A \beta$ plaque variant called cotton wool plaques (Dumanchin et al., 2006). The PS1dE9 mutation is usually used in combination with the human APP Swedish mutation to increase A $\beta$ production and memory deficits in animal models of AD. The $\mathrm{Ca}^{2+}$ dysregulation occurring with the PS1dE9 mutation has only been poorly studied in cell lines and has suggested a regulation of intracellular $\mathrm{Ca}^{2+}$ (Cedazo-Minguez et al., 2002; Nelson et al., 2007) but the effect of the mutation on $\mathrm{Ca}^{2+}$ signaling and contraction of blood vessels has never been studied so far.

\subsection{Contraction of vascular SMC is decreased in PS1dE9}

After demonstrating the expression of dE9 mutation of PS1 in cerebral blood vessels, we first evaluated the consequences of the mutation on the capacity of the cerebral blood vessels to contract in response to agonist stimulation in vivo. Therefore, we develop in vivo contraction measurements by real-time imaging of the cerebral blood vessels stained by IV injection of a fluorescent marker. These experiments have shown that phenylephrine-
A
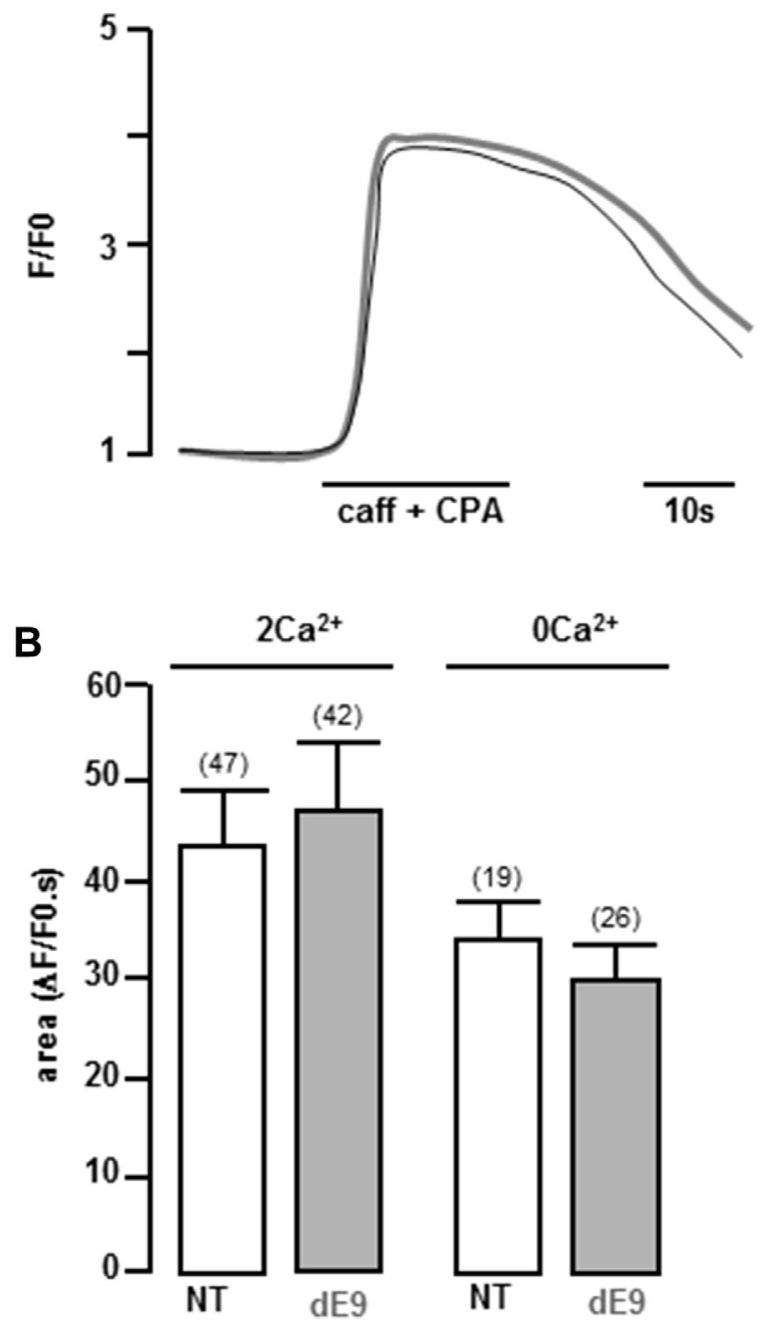

Fig. 7. $\mathrm{Ca}^{2+}$ responses activated by caffeine in the presence of the SERCA blocking agent CPA. (A) Typical $\mathrm{Ca}^{2+}$ responses evoked by $5-\mathrm{mM}$ caffeine $+1-\mu \mathrm{M}$ CPA in the presence of $2 \mathrm{mM}$ of extracellular $\mathrm{Ca}^{2+}$. (B) Statistical analyses of $\mathrm{Ca}^{2+}$ responses measured in NT (black thin trace) and PS1dE9 (gray thick trace) cells. Mean \pm SEM of area under the curve of caffeine-induced $\mathrm{Ca}^{2+}$ responses in the presence of CPA were not affected in the PS1dE9 mutant mice in $2 \mathrm{mM} \mathrm{Ca}^{2+}$-containing or in $\mathrm{Ca}^{2+}$-free external solution. Bar graphs illustrate mean \pm SEM; the number of cells analyzed is indicated in parentheses. Abbreviations: CPA, cyclopiazonic acid; PS1dE9, deletion of exon 9 of PS1; SEM, standard error of the mean.

induced contraction was decreased in PS1dE9 mutants. These results suggest that in addition to modification of vessel architecture (Kelly et al., 2015), the function of cerebral vessels may also be affected in PS1-mutant mouse models of FAD. Our ex vivo experiments showing that the caffeine-activated cerebral vessel contraction was also decreased in PS1dE9 mutants further support the fact that PS1 mutation decreases the capacity of cerebral blood vessels to adapt to vascular stimuli. These results are reminiscent of previous studies revealing the impairment of microvessels responsiveness in patient suffering of mild cognitive impairment (Khalil et al., 2007) and arterial hypoperfusion and CBF dysregulation in AD (Iadecola, 2004; Zlokovic, 2005).

\subsection{Alteration of $\mathrm{Ca}^{2+}$ homeostasis in PS1dE9 VSMC}

In agreement with the decreased vessel reactivity in PS1dE9, the $\mathrm{Ca}^{2+}$ signal produced in response to caffeine stimulation is also decreased in PS1dE9 cerebrovascular SMC. Indeed, the 
caffeine-activated $\mathrm{Ca}^{2+}$ release is shorter in the PS1dE9 mutant. This effect could result from the inhibition of RyR channel by the mutated PS1 or an accelerated $\mathrm{Ca}^{2+}$ pumping by SERCA (PS mutation has been shown to accelerate SERCA pump activity, whereas PS KO decrease the SERCA activity; Green et al., 2008).

\subsubsection{No direct inhibition of RyR channel by PS1dE9 in VSMC}

$\mathrm{N}$-ter of PS1 has been shown to interact with RyR channels when co-expressed in a lipid bilayer (Rybalchenko et al., 2008) or when overexpressed in SH-SY5Y cells (Payne et al., 2013), leading to stimulation of RyR-channel activity (Hayrapetyan et al., 2008; Rybalchenko et al., 2008). Moreover, RyR amplification of InsP3activated $\mathrm{Ca}^{2+}$ signals is increased in PS1M146V knock in mice (Stutzmann et al., 2007). On the opposite, our results show a shorter RyR-mediated caffeine-induced $\mathrm{Ca}^{2+}$ release in PS1dE9. This discrepancy suggests that the putative stimulatory RyR-PS interaction does not occur in VSMC of PS1dE9 mice. In addition, we did not observe any modification in the shape and frequency of $\mathrm{Ca}^{2+}$ sparks which are specific elementary RyR-dependent $\mathrm{Ca}^{2+}$ signals (Arnaudeau et al., 1996; Macrez and Mironneau, 2004). Since $\mathrm{Ca}^{2+}$ sparks reflect transient activation of small clusters of RyR1 and RyR2 channels (Coussin et al., 2000), our results suggest that the spontaneous gating of these RyR channels is not directly affected by the PS1dE9 mutation. PS1M146V mutants have phenotypes reminiscent of features observed in FAD PS carriers and MCI patients, including enhanced neuronal expression of RyR2 (Bruno et al., 2012; Stutzmann et al., 2006). When we analyzed RyR expression restricted to cerebral blood vessels, we did not see an increased in RYR2 expression but show a clear increase in vascular RyR3 expression in PS1dE9 mutants. We have previously shown that the spliced form of RyR3 able to inhibit RyR2 decreases the amplitude of caffeine-induced $\mathrm{Ca}^{2+}$ responses (Boursereau et al., 2015; Dabertrand et al., 2006, 2007), whereas this is unchanged in VSMC from PS1dE9 mice. Similar upregulation of RyR3 that did not affect global $\mathrm{Ca}^{2+}$ homeostasis has been observed in cultured neurons from TgCRND8 mice (Supnet et al., 2010). Together our results suggest that PS1dE9 mutation generates a RyR3-rich blood vessel phenotype where RyR3 upregulation does not inhibit the release through other RyR channels in VSMC. Whether the RyR3 upregulation could occur in the endothelial cell layer and could be involved in the regulation of VSMC remains to be explored.

\subsubsection{Acceleration of $S R \mathrm{Ca}^{2+}$ pumping through SERCA in VSMC from PS1dE9}

Our results show that SR $\mathrm{Ca}^{2+}$ pumping through SERCA activity is increased in PS1dE9 mutants leading to a decreased duration of caffeine-activated $\mathrm{Ca}^{2+}$ signals in vascular myocytes observed in Fig. 3 and a net decreased caffeine-induced CCE observed in Fig. 5A and $\mathrm{B}$. Moreover, CPA (which is a SERCA inhibitor) inhibited the effects of PS1dE9 on caffeine-induced $\mathrm{Ca}^{2+}$ signals, whereas it should not have changed the response if a direct inhibition of the release process had occur in PS1dE9. This result is in agreement with studies showing that SERCA activity is affected by PS mutations (Brunello et al., 2009; Green et al., 2008). Our results are in line with others showing alteration of the kinetics of $\mathrm{Ca}^{2+}$ release from the ER, resulting in faster $\mathrm{Ca}^{2+}$ spike decay in PS1 mutants (McCombs et al., 2010).

Since isoforms of SERCA display specific properties and since the expression of SERCA3 and PLB are increased in PS1dE9, one may speculate that the fast SR refilling by $\mathrm{Ca}^{2+}$ pumping activity is perturbed in VSMC from PS1dE9 mice. Indeed, SERCA3 becomes active when cytosolic $\mathrm{Ca}^{2+}$ reaches high levels during cell stimulation (Dode et al., 2002; Martin et al., 2002) and helps to fast refill of the store on $\mathrm{Ca}^{2+}$ release. In contrast SERCA2, in charge of the basal $\mathrm{Ca}^{2+}$ pumping is not upregulated and would rather be inhibited through increased expression of PLB in PS1dE9. These effects are in good agreement with the profile of fast re-uptake of $\mathrm{Ca}^{2+}$ after caffeine-induced $\mathrm{Ca}^{2+}$ release observed in PS1dE9 VSMC. Defining which SERCA isoform is responsible for the acceleration of $\mathrm{Ca}^{2+}$ pumping in PS1dE9 requires experiments using specific inhibitors of SERCA isoforms.

\subsubsection{No change of $\mathrm{Ca}^{2+}$ store in VSMC from PS1dE9}

A curious aspect of our results is that since the SERCA activity is enhanced by the PS1dE9 mutation, we might have expected an increased SR $\mathrm{Ca}^{2+}$ load and subsequent increase in maximum amplitudes of caffeine-induced $\mathrm{Ca}^{2+}$ release and increased amplitude and frequency of $\mathrm{Ca}^{2+}$ sparks (Mironneau et al., 2001). In VSMC of PS1dE9, we did not see any sign of increased or decreased $\mathrm{Ca}^{2+}$ store in PS1dE9: no change in amplitude of $\mathrm{Ca}^{2+}$ release, no change in amplitude or frequency of $\mathrm{Ca}^{2+}$ sparks and no change in $\mathrm{SR} \mathrm{Ca}{ }^{2+}$ content measured with intraluminal $\mathrm{Ca}^{2+}$ dye Fluo5N (see Fig. S3). This could be explained by the fact that only SERCA3 is upregulated, which limits the increase of $\mathrm{Ca}^{2+}$ re-uptake to high cytosolic $\mathrm{Ca}^{2+}$ conditions achieved only during the release and CCE activated by caffeine.

These results do not fit with the hypothesis of calcium overload of ER stores that has been widely invoked to explain exaggerated $\mathrm{Ca}^{2+}$ release in cells expressing PS mutations (LaFerla, 2002; Leissring et al., 2000; Mattson et al., 2003). Depending on the mutation, PS1 may either prevent or promote passive calcium leak. Our results fit with previous ones showing that PS1dE9 mutants promote passive calcium leak from ER and do not lead to ER $\mathrm{Ca}^{2+}$ overload in cell lines (Nelson et al., 2007; Tu et al., 2006). Moreover, the direct measure of intraluminal $\mathrm{Ca}^{2+}$ concentration by genetically encoded ER-targeted $\mathrm{Ca}^{2+}$ dye in cell lines expressing PS1 or PS2 mutation has revealed no effect or rather a decreased level of $\mathrm{Ca}^{2+}$ within the ER (Brunello et al., 2009; Giacomello et al., 2005; Lee et al., 1996; McCombs et al., 2010; Zatti et al., 2006).

$\mathrm{Ca}^{2+}$ store overload linked to PS mutations results in increased amplitude of $\mathrm{Ca}^{2+}$ release on agonist stimulation in neurons (LaFerla, 2002; Mattson et al., 2003). On the opposite, we show here that the amplitude of caffeine-induced $\mathrm{Ca}^{2+}$ release is unchanged but the duration of the response is shorter in VSMC of PS1dE9 mice. Together, these results suggest that regulation of $\mathrm{Ca}^{2+}$ signals PS1dE9 in VSMC leads to faster SERCA $\mathrm{Ca}^{2+}$ pumping into the SR without overloading the $\mathrm{SR} \mathrm{Ca}^{2+}$ content. In other words, the releasable $\mathrm{Ca}^{2+}$ is equal while more $\mathrm{Ca}^{2+}$ enters the SR. This situation can only be achieved if SR $\mathrm{Ca}^{2+}$ leak and/or SR $\mathrm{Ca}^{2+}$ buffering compensate the increased SR $\mathrm{Ca}^{2+}$ uptake. PS has been shown to function as ER calcium leak channels and mutations in PS may prevent or promote passive calcium leak, which then leads to modifications of $\mathrm{Ca}^{2+}$ store filling (Nelson et al., 2007; Tu et al., 2006). We can therefore speculate that PS mutations could alter a balance between SERCA pump activity and calcium leak from SR which determines the calcium levels in ER. In PS1dE9 VSMC, the balance seems to lead to constant SR $\mathrm{Ca}^{2+}$ load although the SERCA pumping is accelerated.

\subsection{Effect of PS1dE9 mutation or PS1 overexpression}

Regarding recent papers describing that phenotypes observed in Alzheimer's model mice are artifacts of APP and presenilin overexpression rather than true effects of APP or PS1 mutations (Saito et al., 2016), we cannot exclude that the effects we observed in the present paper are not due to PS1 overexpression. However, this does not change the main take home message of our paper, that is, changes in presenilin (either mutation and/or overexpression) affect the $\mathrm{Ca}^{2+}$ signals and contraction in cerebral blood vessels. In addition, since mutation or upregulation in PS1 gene are found in 
familial early-onset $A D$ or sporadic late-onset $A D$ respectively (Borghi et al., 2010), our study remains relevant in the context of AD.

\section{Conclusion}

In conclusion, our results are consistent with the presenilin proteins playing important roles in vascular myocyte by regulating calcium homeostasis and cerebral blood vessel contraction. Here, we show that in native SMC of cerebral arteries, the mutation of PS1 results in an increased SERCA activity and leads to deregulation of agonist-induced $\mathrm{Ca}^{2+}$ signals. The decreased vascular reactivity shown in the present study impairs acute vascular responses to a stimulus, whereas the hyper-contractile phenotype of SMC observed in cerebral vessels of $\mathrm{AD}$ patient or $\mathrm{AD}$ mice (Chow et al., 2007) may affect both the resting state of the blood vessels and their reactivity. These 2 mechanisms (and probably others) may participate to vascular dysfunction and dysregulation of CBF in AD. Our results show for the first time that vascular $\mathrm{SMC} \mathrm{Ca}^{2+}$ signaling and contraction are affected by PS mutation. They also suggest that studying how FAD-related PS mutations (or sporadic AD-related upregulation of PS1) affect cerebrovascular $\mathrm{Ca}^{2+}$ signaling may help to understand the vasculopathy associated with $A D$ progression.

\section{Disclosure statement}

The authors have no actual or potential conflicts of interest.

\section{Acknowledgements}

The authors thank Raphael Pineau and Marie-Paule Algeo (animal facility) for breeding PS1dE9 mice in Bordeaux; Florian Levet and Jean-Baptiste Sibarita (IINS, CNRS UMR 5297) for developing software allowing cellular contraction analysis.

They also thank our funding supports: the Centre National de la Recherche Scientifique (CNRS), the University of Bordeaux, the Agence Nationale pour la Recherche (ANR-10-CESA-002-02, ANR10-MALZ-001-03), and doctoral fellowships from Région Aquitaine to XT and from Ministère de l'Enseignement Supérieur to MCB.

\section{Appendix A. Supplementary data}

Supplementary data associated with this article can be found, in the online version, at http://dx.doi.org/10.1016/j.neurobiolaging. 2017.06.015.

\section{References}

Arnaudeau, S., Macrez-Lepretre, N., Mironneau, J., 1996. Activation of calcium sparks by angiotensin II in vascular myocytes. Biochem. Biophys. Res. Commun. 222, 809-815.

Berridge, M.J., Lipp, P., Bootman, M.D., 2000. The versatility and universality of calcium signalling. Nat. Rev. Mol. Cell Biol. 1, 11-21.

Bezprozvanny, I., Mattson, M.P., 2008. Neuronal calcium mishandling and the pathogenesis of Alzheimer's disease. Trends Neurosci. 31, 454-463.

Boittin, F.X., Coussin, F., Macrez, N., Mironneau, C., Mironneau, J., 1998. Inositol 1,4,5trisphosphate- and ryanodine-sensitive $\mathrm{Ca} 2+$ release channel-dependent $\mathrm{Ca} 2+$ signalling in rat portal vein myocytes. Cell Calcium 23, 303-311.

Boittin, F.X., Macrez, N., Halet, G., Mironneau, J., 1999. Norepinephrine-induced $\mathrm{Ca}(2+)$ waves depend on $\operatorname{Ins} \mathrm{P}(3)$ and ryanodine receptor activation in vascular myocytes. Am. J. Physiol. 277 (1 Pt 1), C139-C151.

Bojarski, L., Herms, J., Kuznicki, J., 2008. Calcium dysregulation in Alzheimer's disease. Neurochem. Int. 52, 621-633.

Borchelt, D.R., Thinakaran, G., Eckman, C.B., Lee, M.K., Davenport, F., Ratovitsky, T., Prada, C.-M., Kim, G., Seekins, S., Yager, D., Slunt, H.H., Wang, R., Seeger, M., Levey, A.I., Gandy, S.E., Copeland, N.G., Jenkins, N.A., Price, D.L., Younkin, S.G., Sisodia, S.S., 1996. Familial Alzheimer's disease-linked presenilin 1 variants elevate $A \beta 1-42 / 1-40$ ratio in vitro and in vivo. Neuron 17, 1005-1013.
Borghi, R., Piccini, A., Barini, E., Cirmena, G., Guglielmotto, M., Tamagno, E. Fornaro, M., Perry, G., Smith, M.A., Garuti, A., Tabaton, M., 2010. Upregulation of presenilin 1 in brains of sporadic, late-onset Alzheimer's disease. J. Alzheimer's Dis. 22, 771-775.

Boursereau, R., Donadieu, A., Dabertrand, F., Dubayle, D., Morel, J.L., 2015. Blood brain barrier precludes the cerebral arteries to intravenously-injected antisense oligonucleotide. Eur. J. Pharmacol. 747, 141-149.

Brochet, D.X., Yang, D., Di Maio, A., Lederer, W.J., Franzini-Armstrong, C., Cheng, H. 2005. Ca2+ blinks: rapid nanoscopic store calcium signaling. Proc. Natl. Acad. Sci. U. S. A. 102, 3099-3104.

Brunello, L., Zampese, E., Florean, C., Pozzan, T., Pizzo, P., Fasolato, C., 2009. Presenilin-2 dampens intracellular Ca2 + stores by increasing $\mathrm{Ca} 2+$ leakage and reducing Ca2+ uptake. J. Cell Mol. Med. 13, 3358-3369.

Bruno, A.M., Huang, J.Y., Bennett, D.A., Marr, R.A., Hastings, M.L., Stutzmann, G.E. 2012. Altered ryanodine receptor expression in mild cognitive impairment and Alzheimer's disease. Neurobiol. Aging 33, 1001.e1-1001.e6.

Campion, D., Flaman, J.M., Brice, A., Hannequin, D., Dubois, B., Martin, C., Moreau, V. Charbonnier, F., Didierjean, O., Tardieu, S., Penet, C., Puel, M., Pasquier, F., Le Doze, F., Bellis, G., Calenda, A., Heilig, R., Martinez, M., Mallet, J., Bellis, M. Clerget-Darpoux, F., Agid, Y., Frebourg, T., 1995. Mutations of the presenilin I gene in families with early-onset Alzheimer's disease. Hum. Mol. Genet. 4, 2373-2377.

Cedazo-Minguez, A., Popescu, B.O., Ankarcrona, M., Nishimura, T., Cowburn, R.F, 2002. The presenilin 1 deltaE9 mutation gives enhanced basal phospholipase $C$ activity and a resultant increase in intracellular calcium concentrations. J. Biol. Chem. 277, 36646-36655.

Chan, S.L., Mayne, M., Holden, C.P., Geiger, J.D., Mattson, M.P., 2000. Presenilin-1 mutations increase levels of ryanodine receptors and calcium release in PC12 cells and cortical neurons. J. Biol. Chem. 275, 18195-18200.

Chow, N., Bell, R.D., Deane, R., Streb, J.W., Chen, J., Brooks, A., Van Nostrand, W. Miano, J.M., Zlokovic, B.V., 2007. Serum response factor and myocardin mediate arterial hypercontractility and cerebral blood flow dysregulation in Alzheimer's phenotype. Proc. Natl. Acad. Sci. U. S. A. 104, 823-828.

Coma, M., Guix, F.X., Ill-Raga, G., Uribesalgo, I., Alameda, F., Valverde, M.A., Muñoz, F.J., 2008. Oxidative stress triggers the amyloidogenic pathway in human vascular smooth muscle cells. Neurobiol. Aging 29, 969-980.

Coussin, F., Macrez, N., Morel, J.L., Mironneau, J., 2000. Requirement of ryanodine receptor subtypes 1 and 2 for $\mathrm{Ca}(2+)$-induced $\mathrm{Ca}(2+)$ release in vascular myocytes. J. Biol. Chem. 275, 9596-9603.

Crook, R., Verkkoniemi, A., Perez-Tur, J., Mehta, N., Baker, M., Houlden, H., Farrer, M. Hutton, M., Lincoln, S., Hardy, J., Gwinn, K., Somer, M., Paetau, A., Kalimo, H. Ylikoski, R., Poyhonen, M., Kucera, S., Haltia, M., 1998. A variant of Alzheimer's disease with spastic paraparesis and unusual plaques due to deletion of exon 9 of presenilin 1. Nat. Med. 4, 452-455.

Dabertrand, F., Fritz, N., Mironneau, J., Macrez, N., Morel, J.L., 2007. Role of RYR3 splice variants in calcium signaling in mouse nonpregnant and pregnant myometrium. Am. J. Physiol. Cell Physiol. 293, C848-C854.

Dabertrand, F., Morel, J.L., Sorrentino, V., Mironneau, J., Mironneau, C., Macrez, N., 2006. Modulation of calcium signalling by dominant negative splice variant of ryanodine receptor subtype 3 in native smooth muscle cells. Cell Calcium 40,11-21.

Dabertrand, F., Nelson, M.T., Brayden, J.E., 2013. Ryanodine receptors, calcium signaling, and regulation of vascular tone in the cerebral parenchymal microcirculation. Microcirculation 20, 307-316.

Davis-Salinas, J., Saporito-Irwin, S.M., Cotman, C.W., Van Nostrand, W.E., 1995 Amyloid $\beta$-protein Induces its Own production in cultured Degenerating cerebrovascular smooth muscle cells. J. Neurochem. 65, 931-934.

Deane, R., Wu, Z., Sagare, A., Davis, J., Du Yan, S., Hamm, K., Xu, F., Parisi, M. LaRue, B., Hu, H.W., Spijkers, P., Guo, H., Song, X., Lenting, P.J., Van Nostrand, W.E., Zlokovic, B.V., 2004a. LRP/Amyloid $\beta$-peptide interaction Mediates Differential brain Efflux of $A \beta$ isoforms. Neuron 43, 333-344.

Deane, R., Wu, Z., Zlokovic, B.V., 2004b. RAGE (Yin) versus LRP (Yang) balance regulates Alzheimer amyloid $\beta$-peptide clearance through Transport across the blood-brain barrier. Stroke 35 (11 suppl 1), 2628-2631.

Dode, L., Vilsen, B., Van Baelen, K., Wuytack, F., Clausen, J.D., Andersen, J.P., 2002 Dissection of the functional differences between sarco(endo)plasmic reticulum Ca2+-ATPase (SERCA) 1 and 3 isoforms by steady-state and transient kinetic analyses. J. Biol. Chem. 277, 45579-45591.

Duff, K., Eckman, C., Zehr, C., Yu, X., Prada, C.M., Perez-tur, J., Hutton, M., Buee, L. Harigaya, Y., Yager, D., Morgan, D., Gordon, M.N., Holcomb, L., Refolo, L., Zenk, B. Hardy, J., Younkin, S., 1996. Increased amyloid-beta42(43) in brains of mice expressing mutant presenilin 1 . Nature 383, 710-713.

Dumanchin, C., Tournier, I., Martin, C., Didic, M., Belliard, S., Carlander, B., Rouhart, F, Duyckaerts, C., Pellissier, J.F., Latouche, J.B., Hannequin, D., Frebourg, T., Tosi, M., Campion, D., 2006. Biological effects of four PSEN1 gene mutations causing Alzheimer disease with spastic paraparesis and cotton wool plaques. Hum. Mutat. 27, 1063.

Elder, G.A., Tezapsidis, N., Carter, J., Shioi, J., Bouras, C., Li, H.C., Johnston, J.M. Efthimiopoulos, S., Friedrich Jr., V.L., Robakis, N.K., 1996. Identification and neuron specific expression of the S182/presenilin I protein in human and rodent brains. J. Neurosci. Res. 45, 308-320.

Fischer, V.W., Siddiqi, A., Yusufaly, Y., 1990. Altered angioarchitecture in selected areas of brains with Alzheimer's disease. Acta Neuropathol. 79, 672-679.

Frackowiak, J., Sukontasup, T., Potempska, A., Mazur-Kolecka, B., 2004. Lysosoma deposition of $A \beta$ in cultures of brain vascular smooth muscle cells is enhanced by iron. Brain Res. 1002, 67-75. 
Gama Sosa, M.A., Gasperi, R.D., Rocher, A.B., Wang, A.C., Janssen, W.G., Flores, T., Perez, G.M., Schmeidler, J., Dickstein, D.L., Hof, P.R., Elder, G.A., 2010. Age-related vascular pathology in transgenic mice expressing presenilin 1-associated familial Alzheimer's disease mutations. Am. J. Pathol. 176, 353-368.

Giacomello, M., Barbiero, L., Zatti, G., Squitti, R., Binetti, G., Pozzan, T., Fasolato, C., Ghidoni, R., Pizzo, P., 2005. Reduction of Ca2+ stores and capacitative Ca2+ entry is associated with the familial Alzheimer's disease presenilin-2 T122R mutation and anticipates the onset of dementia. Neurobiol. Dis. 18, 638-648.

Green, K.N., Demuro, A., Akbari, Y., Hitt, B.D., Smith, I.F., Parker, I., LaFerla, F.M., 2008. SERCA pump activity is physiologically regulated by presenilin and regulates amyloid beta production. J. Cel. Biol. 181, 1107-1116.

Hayrapetyan, V., Rybalchenko, V., Rybalchenko, N., Koulen, P., 2008. The N-terminus of presenilin-2 increases single channel activity of brain ryanodine receptors through direct protein-protein interaction. Cell Calcium 44, 507-518.

Herms, J., Schneider, I., Dewachter, I., Caluwaerts, N., Kretzschmar, H., Van Leuven, F., 2003. Capacitive calcium entry is directly attenuated by mutant presenilin-1, independent of the expression of the amyloid precursor protein. J. Biol. Chem. 278, 2484-2489.

Iadecola, C., 2004. Neurovascular regulation in the normal brain and in Alzheimer's disease. Nat. Rev. Neurosci. 5, 347-360.

Ito, E., Oka, K., Etcheberrigaray, R., Nelson, T.J., McPhie, D.L., Tofel-Grehl, B., Gibson, G.E., Alkon, D.L., 1994. Internal Ca2+ mobilization is altered in fibroblasts from patients with Alzheimer disease. Proc. Natl. Acad. Sci. U. S. A. 91, 534-538.

Jin, H., Sanjo, N., Uchihara, T., Watabe, K., St George-Hyslop, P., Fraser, P.E., Mizusawa, H., 2010. Presenilin-1 holoprotein is an interacting partner of sarco endoplasmic reticulum calcium-ATPase and confers resistance to endoplasmic reticulum stress. J. Alzheimer's Dis. 20, 261-273.

Kelly, P., McClean, P.L., Ackermann, M., Konerding, M.A., Hölscher, C., Mitchell, C.A., 2015. Restoration of cerebral and systemic microvascular architecture in APP/ PS1 transgenic mice Following Treatment with Liraglutide ${ }^{\mathrm{TM}}$. Microcirculation 22, 133-145.

Khachaturian, Z.S., 1989. Calcium, membranes, aging and Alzheimer's disease: introduction and overview. Ann. New York Acad. Sci. 568, 1-4.

Khalil, Z., LoGiudice, D., Khodr, B., Maruff, P., Masters, C., 2007. Impaired peripheral endothelial microvascular responsiveness in Alzheimer's disease. J. Alzheimer's Dis. 11, 25-32.

Kitaguchi, H., Ihara, M., Saiki, H., Takahashi, R., H, T., 2007. Capillary beds are decreased in Alzheimer's disease, but not in Binswanger's disease. Neurosci. Lett. 417, 128-131.

LaFerla, F.M., 2002. Calcium dyshomeostasis and intracellular signalling in Alzheimer's disease. Nat. Rev. Neurosci. 3, 862-872.

Le Blanc, C., Mironneau, C., Barbot, C., Henaff, M., Bondeva, T., Wetzker, R., Macrez, N., 2004. Regulation of vascular L-type Ca2+ channels by phosphatidylinositol 3,4,5-trisphosphate. Circ. Res. 95, 300-307.

Lee, M.K., Slunt, H.H., Martin, L.J., Thinakaran, G., Kim, G., Gandy, S.E., Seeger, M., Koo, E., Price, D.L., Sisodia, S.S., 1996. Expression of presenilin 1 and 2 (PS1 and PS2) in human and murine tissues. J. Neurosci. 16, 7513-7525.

Leissring, M.A., Akbari, Y., Fanger, C.M., Cahalan, M.D., Mattson, M.P., LaFerla, F.M., 2000. Capacitative calcium entry deficits and elevated luminal calcium content in mutant presenilin-1 knockin mice. J. Cel. Biol. 149, 793-798.

MacLennan, D.H., Kranias, E.G., 2003. Phospholamban: a crucial regulator of cardiac contractility. Nat. Rev. Mol. Cell Biol. 4, 566-577.

Macrez, N., Mironneau, J., 2004. Local Ca2 + signals in cellular signalling. Curr. Mol. Med. 4, 263-275.

Magi, S., Castaldo, P., Macri, M.L., Maiolino, M., Matteucci, A., Bastioli, G., Gratteri, S., Amoroso, S., Lariccia, V., 2016. Intracellular calcium dysregulation: Implications for Alzheimer's disease. Biomed. Res. Int. 2016, 6701324.

Marchesi, V.T., 2014. Alzheimer's disease and CADASIL are heritable, adult-onset dementias that both involve damaged small blood vessels. Cell Mol. Life Sci. 71, 949-955.

Martin, V., Bredoux, R., Corvazier, E., Van Gorp, R., Kovacs, T., Gelebart, P., Enouf, J., 2002. Three novel sarco/endoplasmic reticulum Ca2+-ATPase (SERCA) 3 isoforms. Expression, regulation, and function of the membranes of the SERCA3 family. J. Biol. Chem. 277, 24442-24452.

Mattson, M.P., Duan, W., Guo, Z., 2003. Meal size and frequency affect neuronal plasticity and vulnerability to disease: cellular and molecular mechanisms. J. Neurochem. 84, 417-431.

McCarthy, J.V., Twomey, C., Wujek, P., 2009. Presenilin-dependent regulated intramembrane proteolysis and $\gamma$-secretase activity. Cell Mol. Life Sci. 66, 1534-1555.

McCombs, J.E., Gibson, E.A., Palmer, A.E., 2010. Using a genetically targeted sensor to investigate the role of presenilin-1 in ER Ca2+ levels and dynamics. Mol. bioSystems 6, 1640-1649.

Mironneau, J., Arnaudeau, S., Macrez-Lepretre, N., Boittin, F.X., 1996. Ca2+ sparks and $\mathrm{Ca} 2+$ waves activate different $\mathrm{Ca}(2+)$-dependent ion channels in single myocytes from rat portal vein. Cell Calcium 20, 153-160.
Mironneau, J., Coussin, F., Jeyakumar, L.H., Fleischer, S., Mironneau, C., Macrez, N., 2001. Contribution of ryanodine receptor subtype 3 to ca2 + responses in Ca2+overloaded cultured rat portal vein myocytes. J. Biol. Chem. 276, 11257-11264.

Morel, J., Fritz, N., Dabertrand, F., Macrez, N., 2007. Ca2+ releasing channels of smooth muscle sarcoplasmic reticulum. In: Savineau, J.-P. (Ed.), New Frontiers in Smooth Muscle Biology and Physiology. Transworld Research Network; Kerala, pp. 131-150.

Nelson, M.T., Cheng, H., Rubart, M., Santana, L.F., Bonev, A.D., Knot, H.J., Lederer, W.J., 1995. Relaxation of arterial smooth muscle by calcium sparks. Science 270 , 633-637.

Nelson, O., Tu, H., Lei, T., Bentahir, M., de Strooper, B., Bezprozvanny, I., 2007. Familial Alzheimer disease-linked mutations specifically disrupt Ca2+ leak function of presenilin 1. J. Clin. Invest. 117, 1230-1239.

Payne, A.J., Gerdes, B.C., Naumchuk, Y., McCalley, A.E., Kaja, S., Koulen, P., 2013. Presenilins regulate the cellular activity of ryanodine receptors differentially through isotype-specific N-terminal cysteines. Exp. Neurol. 250, 143-150.

Rogaev, E.I., Sherrington, R., Rogaeva, E.A., Levesque, G., Ikeda, M., Liang, Y., Chi, H. Lin, C., Holman, K., Tsuda, T., Mar, L., Sorbi, S., Nacmias, B., Piacentini, S. Amaducci, L., Chumakov, I., Cohen, D., Lannfelt, L., Fraser, P.E., Rommens, J.M., George-Hyslop, P.H., 1995. Familial Alzheimer's disease in kindreds with missense mutations in a gene on chromosome 1 related to the Alzheimer's disease type 3 gene. Nature 376, 775-778.

Rybalchenko, V., Hwang, S.Y., Rybalchenko, N., Koulen, P., 2008. The cytosolic Nterminus of presenilin-1 potentiates mouse ryanodine receptor single channel activity. Int. J. Biochem. Cell Biol. 40, 84-97.

Saito, T., Matsuba, Y., Yamazaki, N., Hashimoto, S., Saido, T.C., 2016. Calpain activation in Alzheimer's model mice is an artifact of APP and presenilin overexpression. J. Neurosci. 36, 9933-9936.

Shilling, D., Mak, D.-O.D., Kang, D.E., Foskett, J.K., 2012. Lack of evidence for presenilins as endoplasmic reticulum Ca2+ leak channels. J. Biol. Chem. 287, 10933-10944.

Smith, I.F., Boyle, J.P., Vaughan, P.F., Pearson, H.A., Cowburn, R.F., Peers, C.S., 2002 $\mathrm{Ca}(2+)$ stores and capacitative $\mathrm{Ca}(2+)$ entry in human neuroblastoma ( $\mathrm{SH}-$ SY5Y) cells expressing a familial Alzheimer's disease presenilin-1 mutation. Brain Res. 949, 105-111.

Smith, I.F., Green, K.N., LaFerla, F.M., 2005. Calcium dysregulation in Alzheimer's disease: recent advances gained from genetically modified animals. Cell Calcium 38, 427-437.

Somavarapu, A.K., Kepp, K.P., 2016. The dynamic mechanism of presenilin-1 function: sensitive gate dynamics and loop unplugging control protein access Neurobiol. Dis. 89, 147-156.

Stutzmann, G.E., Smith, I., Caccamo, A., Oddo, S., Laferla, F.M., Parker, I., 2006 Enhanced ryanodine receptor recruitment contributes to $\mathrm{Ca} 2+$ disruptions in young, adult, and aged Alzheimer's disease mice. J. Neurosci. 26, 5180-5189.

Stutzmann, G.E., Smith, I., Caccamo, A., Oddo, S., Parker, I., Laferla, F. 2007. Enhanced ryanodine-mediated calcium release in mutant PS1-expressing Alzheimer's mouse models. Ann. N. Y Acad. Sci. 1097, 265-277.

Supnet, C., Noonan, C., Richard, K., Bradley, J., Mayne, M., 2010. Up-regulation of the type 3 ryanodine receptor is neuroprotective in the TgCRND8 mouse model of Alzheimer's disease. J. Neurochem. 112, 356-365.

Thinakaran, G., Borchelt, D.R., Lee, M.K., Slunt, H.H., Spitzer, L., Kim, G., Ratovitsky, T. Davenport, F., Nordstedt, C., Seeger, M., Hardy, J., Levey, A.I., Gandy, S.E., Jenkins, N.A., Copeland, N.G., Price, D.L., Sisodia, S.S., 1996. Endoproteolysis of presenilin 1 and accumulation of processed Derivatives in vivo. Neuron 17 $181-190$.

Toglia, P., Cheung, K.-H., Mak, D.-O.D., Ullah, G., 2016. Impaired mitochondrial function due to familial Alzheimer's disease-causing presenilins mutants via Ca2+ disruptions. Cell Calcium 59, 240-250.

Tu, H., Nelson, O., Bezprozvanny, A., Wang, Z., Lee, S.F., Hao, Y.H., Serneels, L., De Strooper, B., Yu, G., Bezprozvanny, I., 2006. Presenilins form ER Ca2+ leak channels, a function disrupted by familial Alzheimer's Disease-linked mutations. Cell 126, 981-993.

Vandesompele, J., De Preter, K., Pattyn, F., Poppe, B., Van Roy, N., De Paepe, A. Speleman, F., 2002. Accurate normalization of real-time quantitative RT-PCR data by geometric averaging of multiple internal control genes. Genome Biol. 3. RESEARCH0034.

Wellman, G.C., Nathan, D.J., Saundry, C.M., Perez, G., Bonev, A.D., Penar, P.L. Tranmer, B.I., Nelson, M.T., 2002. Ca2 + sparks and their function in human cerebral arteries. Stroke 33, 802-808.

Wu, B., Yamaguchi, H., Lai, F.A., Shen, J., 2013. Presenilins regulate calcium homeostasis and presynaptic function via ryanodine receptors in hippocampal neurons. Proc. Natl. Acad. Sci. 110, 15091-15096.

Zatti, G., Burgo, A., Giacomello, M., Barbiero, L., Ghidoni, R., Sinigaglia, G., Florean, C., Bagnoli, S., Binetti, G., Sorbi, S., Pizzo, P., Fasolato, C., 2006. Presenilin mutations linked to familial Alzheimer's disease reduce endoplasmic reticulum and Golgi apparatus calcium levels. Cell Calcium 39, 539-550.

Zlokovic, B.V., 2005. Neurovascular mechanisms of Alzheimer's neurodegeneration. Trends Neurosci. 28, 202-208. 